\title{
A Practical Approach to Localize Simultaneous Triple Open-Switches for a PWM Inverter-Fed Permanent Magnet Synchronous Machine Drive System
}

\author{
Jae-Hwan Song and Kyeong-Hwa Kim * \\ Department of Electrical and Information Engineering, Seoul National University of Science and Technology, \\ 232 Gongneung-ro, Nowon-gu, Seoul 01811, Korea; ssongcheck@naver.com \\ * Correspondence: k2h1@seoultech.ac.kr; Tel.: +82-2-970-6406; Fax: +82-2-978-2754
}

Received: 12 December 2017; Accepted: 31 December 2017; Published: 2 January 2018

\begin{abstract}
In order to overcome the limitations of conventional diagnosis methods, this paper proposes a reliable and practical on-line fault localization scheme for a pulse width modulation (PWM) inverter-fed permanent magnet synchronous machine (PMSM) drive system even when the inverter has simultaneous open faults in up to three switches. An open-switch fault is usually initiated by an accidental over-current, or electrical and thermal stresses. This fault may induce crucial secondary damage in the drive system since it is easily propagated and produces a continuous harmful effect on other system components. The open-switch faults in inverters often occur in a very complicated manner. Due to this reason, it was only recently that real-time diagnosis schemes under the open-switch faults in multiple switches have been presented in a few references. However, to alleviate the complexity and exactness issues, most of the conventional diagnosis schemes have considered the open faults only in two simultaneous switches until now, which is not generally the case. Even though the fault detection is simple and immediate, the exact fault localization is not a simple task, especially when there are open faults in three simultaneous switches because different open-switch fault locations may develop the same fault signature. To deal with such a problem, free-wheeling mode detection is introduced in this paper for the purpose of identifying the exact fault group and the faulty switch location. Then main objective of this paper is to realize a reliable fault localization algorithm under the condition of simultaneous open-switches (up to three) on an online basis without requiring any extra hardware or sensors in order that the algorithm can be easily installed in main CPU of a commercial drive system. For this purpose, the open faults in simultaneous switches are categorized into seven different fault groups. The entire system is implemented on a digital controller by using TMS320F28335 digital signal processor (DSP). The experimental results are presented under various open fault conditions to validate the usefulness of the proposed open-switch fault localization scheme.
\end{abstract}

Keywords: free-wheeling mode detection; PWM inverter; reliable on-line fault localization; seven fault groups; three simultaneous open-switches

\section{Introduction}

In recent years, reliability, continuity, and fault-related issues have been receiving lots of research attention in automation or industrial processes employing a pulse width modulation (PWM) inverter-fed permanent magnet synchronous machine (PMSM) drive systems. Furthermore, in some drive applications such as vehicle and railway transportation, a high degree of reliability and safety must be continuously achieved, even in accident or fault situations, which makes the fault diagnosis of AC machine drive systems as one of the primary concerns [1]. Since a fault in such applications 
often leads to a critical problem, as well as increased losses caused by abrupt system operation halts, there has been a strong need to enhance the system stability and sustainability.

In general, PWM inverter-fed PMSM drive systems are usually subject to various faults in different system components such as the power converter module, controller, and sensing devices [2]. The faults in drive systems often trigger a reduced system lifetime and high repair costs due to unscheduled maintenance, eventually causing disastrous accidents in an extreme case. For this reason, a considerable number of studies has been devoted to developing fault diagnosis schemes. The main objective is to realize online fault detection and fault localization algorithms without requiring any additional hardware components or extra sensors. Other desirable requirements are speed, simplicity, and easiness in the algorithm to such an extent that the diagnosis scheme can be installed in a commercial drive system without requiring much computational burden and a large amount of CPU resources.

Recently, several survey papers have reviewed the faults in drive systems with statistical approaches. According to a recent industry study, power components and gate control circuits are known to be the components most susceptible to failure in electric machine drive systems $[3,4]$. In particular, it has been estimated that about $38 \%$ of the faults in industrial AC drives are due to failures of semiconductor power devices. The average downtime cost in different industries caused by unscheduled maintenance events has been investigated [5]. The propensity of several faults occurring in AC machine drives has been analyzed in detail. According to this study, it is known that $63 \%$ of the users experience the faults in drive systems in the first 12 months of operation. In particular, $70 \%$ of these faults are related to the failures in power components [6]. The behavior of a voltage source inverter-fed induction machine drive has been investigated considering key fault conditions in the converter [7]. In recent times, the researches on fault diagnosis scheme have been steadily expanding into the application areas such as the grid-connected inverters [8], renewable energy systems [9], and electric or hybrid vehicles [10].

A failure in semiconductor power devices are classified as a short-circuit fault or an open-circuit fault. The short-circuit fault is more critical and requires immediate measures to shut down the system. Most of the short-circuit detections and protections depend on hardware-based methods since the time between the fault initiation and failure is very small. On the other hand, the open-circuit fault does not essentially make the system shut down. However, this fault may lead to a severe secondary fault in the drive system due to electrical and thermal stresses if it remains undetected for a long time, eventually resulting in system outages and high repair costs [11].

There have been intensive studies regarding the development of fault-tolerant systems to allow the continuity of system operation over the last years [11-13]. A fault-tolerant routine is generally accomplished in four main steps, which are the fault detection, including the identification of fault location, the isolation of faulty components, hardware reconfiguration, and post-fault control optimization. Following these procedures, a fault-tolerant control of three-phase power converter for a PMSM has been studied in a fully automated way by connecting the isolated motor phase to the midpoint of the capacitor bank in DC link [13]. The success of a fault-tolerant system is mainly dependent upon the precision and speed of both the fault detection and identification of the fault location. However, this scheme usually requires large back-up equipment to replace a damaged component in the stage of hardware reconfiguration, which is often the cause of increased cost, size, and complexity of the system. Moreover, available system output may be significantly reduced in post-fault operation. Thus, a rapid and proper action with the knowledge of exact fault location can be a more practical and simpler alternative in a commercial drive system.

The fault detection methods can be categorized as current-based approaches, voltage-based approaches, observer-based techniques, and intelligent control methods such as the fuzzy logic and knowledge-based models. The current-based approaches use average current Park's vector [14], current residual vector between the estimator and system [15], pattern of the stator currents by constructing a signature vector in the $d q$ frame [16], or the normalized DC current to consider load currents [17]. Other methods detect open-switch faults by using the average value of reference current errors [18]. 
Also, the fault detection based on the average absolute values of normalized currents has been presented to implement the detection irrespective of operating conditions $[19,20]$. Other studies have considered the simultaneous open faults in inverter multiple switches and detected fault occurrence by using the current harmonics [1,21], moving window-based current signals [22], and non-zero phase current information [23].

Alternative fault diagnosis methods use a voltage-based approach for open-switch fault detection. To judge the fault occurrence, the measured voltage errors between the normal inverter and faulty case have been employed [24]. Also, a fault diagnosis method using the sectoral average residuals of the pole voltages has been presented in order to improve the performance of the voltage measurement-based methods [25]. The fault detection based on the measurement of the pole voltage and its duration time has been reported for neutral-point-clamped inverter [26]. A fault detection circuit for insulated-gate bipolar transistors (IGBT) based on the gate voltage behavior has been presented [27]. However, the usage of voltage sensors increases the cost and complexity of the detection system. Alternatively, in order to simplify the detecting circuits and get rid of the requirement of high cost voltage sensors, collector-emitter voltages of the lower power switches in inverter have been acquired indirectly by using a high speed diagnostic photocoupler [28]. Other scheme use field-programmable gate arrays (FPGAs) for fault diagnosis of power converters [29]. However, the requirement of extra sensors or components is not desirable in industrial drive applications. Thus, fault diagnosis methods without requiring any extra sensors or hardware have been also investigated by using the operating characteristic of machines [30] or by comparing the normalized reference voltages and estimated voltages [31].

Instead of using the current or voltage-based approaches, other fault diagnosis methods use an observer-based technique [32], the wavelet transformation-based switching faults detection [33], model-based approach [34], and a model reference adaptive system (MRAS) [35]. These techniques are preferred in industrial applications because they do not require the installation of extra hardware. However, the model-based approaches such as observer or MRAS scheme usually require sufficiently accurate information on all the system parameters.

Other approaches use an intelligent control method such as fuzzy logic [36] and knowledge-based models [12] for fault detection. However, these methods have a major drawback of large computational burden due to the complexity of the diagnosis algorithms. Consequently, the adoption of such algorithms in a standard drive system is not easy.

The open-switch faults in an inverter often occur in a very complicated manner. Due to this reason, it was only recently in a few references that real-time diagnosis schemes for open-switch faults in multiple switches have been presented. Even though the fault detection is simple and immediate, the exact fault localization is not simple task, especially when open faults in three multiple switches occur in various types of combination because different open-switch fault locations may develop the same fault signature. Hence, until now conventional diagnosis methods confine the fault localization problem to only the case of the open faults in two simultaneous switches $[1,16,18,19,28,35]$ due to the complexity and precision issues in the case of open faults in more than two switches, even though this is not generally the case.

In order to overcome the limitations in the existing methods, this paper proposes a reliable and practical on-line fault localization scheme for a PWM inverter-fed PMSM drive system, even when the inverter has simultaneous open faults in up to three switches. An open-switch fault is usually initiated by an accidental over-current or electrical and thermal stresses. This fault may induce crucial secondary damage in the drive system since it is easily propagated and produce a continuous harmful effect on other system components. To overcome the limitation in the conventional diagnosis methods and to avoid the complexity in fault localization, the open faults in multiple switches are classified in seven different categories. By using the fault signature developed by each seven fault group as well as by introducing free-wheeling mode detection, the open faults in multiple switches can be identified in a reliable and systematic way. In addition, rather than confining the number of simultaneous open-switches to only two, the proposed scheme aims to extend the open fault problem in multiple 
switches into a general case. The main objective is to realize a rapid and reliable online fault localization algorithm under the condition of simultaneous open-switches (up to three) without requiring any extra hardware or sensors in order that the algorithm can be easily installed in the main CPU of a commercial drive system. The entire fault diagnosis scheme is implemented on a digital controller by using a TMS320F28335digital signal processor (DSP) [37]. The experimental results for various scenarios of open faults in multiple switches to verify the usefulness of the proposed open-switch fault localization scheme.

\section{Open-Switch Faults in a PWM Inverter}

Figure 1 shows the configuration of a three-phase PWM inverter-fed PMSM drive system, in which the PWM inverter consists of six active switches and six free-wheeling diodes. In this figure, $S_{x}$ and $D_{x}$ denote the symbol of switches and diodes for $x=1,2, \ldots 6$, and $v_{a o}, v_{b o}$ and $v_{c o}$ represent the terminal voltages. Whereas the terminal voltages are uniquely determined only by the switching function under the normal operating condition without open-switch fault, they are dependent on the direction of phase current under the open-switch fault condition [35]. Detailed analysis regarding the terminal voltage deviation according to the conduction of free-wheeling diode under the open-switch fault is presented in $[23,35]$.

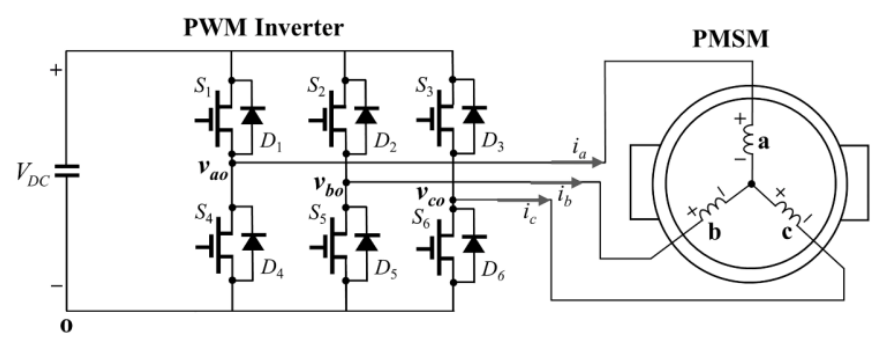

Figure 1. Configuration of a three-phase PWM (pulse width modulation) inverter-fed PMSM (permanent magnet synchronous machine) drive system.

The deviation in terminal voltages caused by the open-switch fault directly influences the generation of phase currents. Since it distorts sinusoidal phase currents, the current waveform can be useful to detect the fault occurrence as well as its location. For example, when the open-switch fault occurs in switch $S_{1}$, positive $a$-phase current can flow only through $D_{4}$ path, making the terminal voltage $v_{a o}$ equal to zero. Since the terminal voltage with $V_{D C}$ cannot be applied to $a$-phase, there are no positive current waveforms in $a$-phase.

In general, commercial AC machine drive systems are implemented with only phase current sensing devices without voltage measurement devices. Thus, to adopt the fault detection and fault localization algorithm in a practical drive system, it is often preferred to realize the fault diagnosis scheme by using only the current information on an online basis. One of the important issues in the fault diagnosis scheme of an inverter-fed PMSM drive is the early detection of faults before the fault expands widely to other components due to the current and thermal stresses as well as mechanical vibration. Another important issue is to find out its source or location correctly without "false alarms".

The open-switch faults in inverters often occur in a very complicated manner. Especially, when open faults occur in multiple switches in various types of combination, exact fault localization is not easy because different open fault locations may present the same fault signature. Due to this complexity, the existing diagnosis methods confine the fault localization problem to the case of the open faults in two simultaneous switches. In order to overcome this limitation, this paper deals with a reliable open fault localization method for up to three simultaneous open-switches. In addition, for the purpose of alleviating the complexity in diagnosis algorithm, the open faults in multiple switches up to three are classified into seven different groups. Because each fault group produces 
unique fault signature in phase current waveforms, the decision-making process to identify faulty switches is more straightforward and systematic. For this aim, the open-switch faults are categorized as seven fault groups in this paper, which are expressed as follows:

$$
\begin{aligned}
& \mathrm{FG}_{1}=\left\{\left(S_{1}\right),\left(S_{2}\right),\left(S_{3}\right),\left(S_{4}\right),\left(S_{5}\right),\left(S_{6}\right)\right\} \\
& \mathrm{FG}_{2}=\left\{\left(S_{1} S_{4}\right),\left(S_{2} S_{5}\right),\left(S_{3} S_{6}\right)\right\} \\
& \mathrm{FG}_{3}=\left\{\left(S_{1} S_{5}\right),\left(S_{1} S_{6}\right),\left(S_{2} S_{4}\right),\left(S_{2} S_{6}\right),\left(S_{3} S_{5}\right),\left(S_{3} S_{4}\right)\right\} \\
& \mathrm{FG}_{4}=\left\{\left(S_{1} S_{2}\right),\left(S_{1} S_{3}\right),\left(S_{2} S_{3}\right),\left(S_{4} S_{5}\right),\left(S_{4} S_{6}\right),\left(S_{5} S_{6}\right)\right\} \\
& \mathrm{FG}_{5}=\left\{\left(S_{1} S_{2} S_{6}\right),\left(S_{1} S_{3} S_{5}\right),\left(S_{1} S_{5} S_{6}\right),\left(S_{2} S_{3} S_{4}\right),\left(S_{2} S_{4} S_{6}\right),\left(S_{3} S_{4} S_{5}\right)\right\} \\
& \mathrm{FG}_{6}=\left\{\left(S_{1} S_{4} S_{2}\right),\left(S_{1} S_{4} S_{3}\right),\left(S_{2} S_{5} S_{1}\right),\left(S_{2} S_{5} S_{3}\right),\left(S_{3} S_{6} S_{1}\right),\left(S_{3} S_{6} S_{2}\right)\right\} \\
& \mathrm{FG}_{7}=\left\{\left(S_{1} S_{4} S_{5}\right),\left(S_{1} S_{4} S_{6}\right),\left(S_{2} S_{5} S_{4}\right),\left(S_{2} S_{5} S_{6}\right),\left(S_{3} S_{6} S_{4}\right),\left(S_{3} S_{6} S_{5}\right)\right\}
\end{aligned}
$$

where $\mathrm{FG}_{1}$ through $\mathrm{FG}_{7}$ denote seven different fault groups according to the number and position of faulty switches, respectively, and the variables in parenthesis denote all elements in each fault group. In these fault groups, the group $\mathrm{FG}_{1}$ denotes the open fault in single switch. The fault groups $\mathrm{FG}_{2}$ through $\mathrm{FG}_{4}$ represent the open fault in two simultaneous switches and these groups are further divided according to the location of the two faulty switches. The group $\mathrm{FG}_{2}$ has the open fault in all the switches of a one-phase inverter leg. In the group $\mathrm{FG}_{3}$, one of two open-switches occurs in the upper leg and the other in the lower leg. On the other hand, the group $\mathrm{FG}_{4}$ has two open-switches either only in the upper leg or only in the lower leg. The fault groups $\mathrm{FG}_{5}$ through $\mathrm{FG}_{7}$ represent the open fault in three simultaneous switches depending on the location of the faulty switches. In the group $\mathrm{FG}_{5}$, the open-switches occur in three different inverter legs. The group $\mathrm{FG}_{6}$ has three open-switches in the entire switches of one-phase inverter leg with one additional upper switch. On the other hand, the group $\mathrm{FG}_{7}$ has three open-switches in the entire switches of one-phase inverter leg with one additional lower switch. Depending on the number and position of faulty switches, each group has a different fault signature in the phase current waveforms.

Even though the open-switch fault detection is simple and immediate, the realization of a reliable faulty switch localization scheme is not a simple task because the open-switch faults occur in a very complicated manner with various combinations of multiple switches. Even, some simultaneous open-switches occurring in different locations may produce exactly the same fault signature in phase current waveforms. Figures 2 and 3 show the experimental results for this case.

Figure 2 shows the experimental results for three-phase currents under the simultaneous open-switch faults in $S_{1}$ and $S_{2}$ of $\mathrm{FG}_{4}$, and under the simultaneous open-switch faults in $S_{1}, S_{2}$ and $S_{6}$ of $F_{5}$, respectively. It is clearly observed that these different faults provide the same three-phase current waveforms. For both the cases, positive $a$-phase and positive $b$-phase currents cannot flow due to the open-switch faults in $S_{1}$ and $S_{2}$. In addition, negative $c$-phase current does not exist regardless of the open-switch fault in $S_{6}$ due to the absence of positive current supply through both $a$-phase and $b$-phase. As a result, positive $a$-phase and $b$-phase currents as well as negative $c$-phase current are absent in either case, even if the open-switch faults occured in different locations.

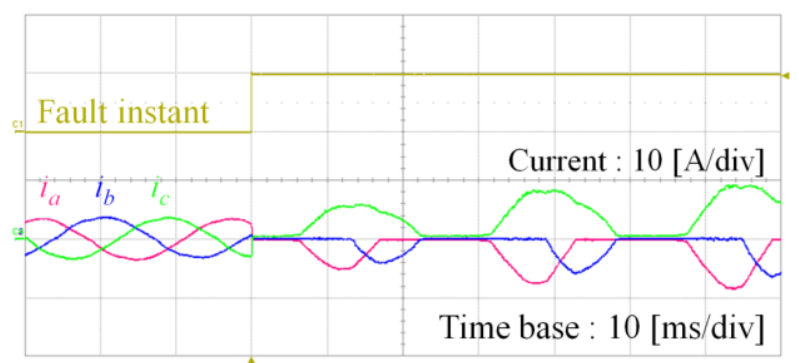

(a)

Figure 2. Cont. 


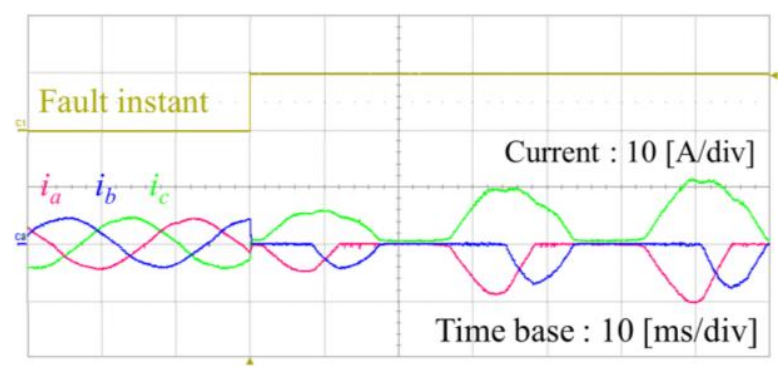

(b)

Figure 2. Experimental results for three-phase currents under multiple open-switch faults. (a) Under open-switch faults in $S_{1}$ and $S_{2}$ of $\mathrm{FG}_{4} ;(\mathbf{b})$ Under open-switch faults in $S_{1}, S_{2}$ and $S_{6}$ of FG .

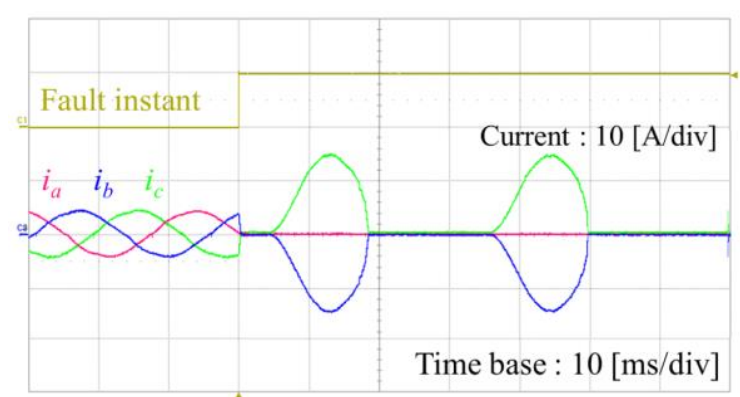

(a)

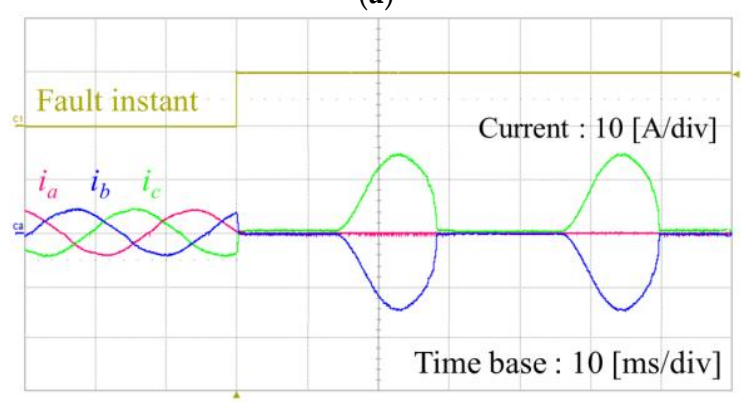

(b)

Figure 3. Experimental results for three-phase currents under multiple open-switch faults. (a) Under open-switch faults in $S_{1}, S_{2}$ and $S_{4}$ of $\mathrm{FG}_{6} ;(\mathbf{b})$ Under open-switch faults in $S_{1}, S_{4}$ and $S_{6}$ of $\mathrm{FG}_{7}$.

Figure 3 shows the experimental results for three-phase currents under the simultaneous open-switch faults in $S_{1}, S_{2}$ and $S_{4}$ of $\mathrm{FG}_{6}$, and under the simultaneous open-switch faults in $S_{1}$, $S_{4}$ and $S_{6}$ of $\mathrm{FG}_{7}$, respectively. These two fault conditions have the open faults in $S_{1}$ and $S_{4}$ in common. Due to the open faults in the entire switches of $a$-phase leg, the inverter cannot develop $a$-phase current, making $b$-phase and c-phase the only possible path for the current. Under the simultaneous open-switch faults in $S_{1}, S_{2}$ and $S_{4}$, positive $b$-phase current cannot flow due to the open-switch in $S_{2}$. Additionally, negative $c$-phase current does not exist due to the absence of positive current supply through $b$-phase. As a result, positive $c$-phase and negative $b$-phase currents are only possible under the simultaneous open-switch faults in $S_{1}, S_{2}$ and $S_{4}$ as shown in Figure 3a. Similar analysis can be applied for the simultaneous open-switch faults in $S_{1}, S_{4}$ and $S_{6}$. In this condition, there are no $a$-phase current and no negative $c$-phase current as well, due to open-switch. Additionally, positive $b$-phase current does not exist due to the absence of negative current path. Thus, as shown in Figure $3 b$, positive $c$-phase and negative $b$-phase currents are only possible, which is very similar to the result in Figure 3a. 
In addition to these results in Figures 2 and 3, it is worth mentioning that all the fault conditions in $\mathrm{FG}_{4}$ have their counterparts in $\mathrm{FG}_{5}$ in view of giving exactly the same fault signature in phase current waveforms. In other words, one fault condition in $\mathrm{FG}_{4}$ has the same fault signature with one in $\mathrm{FG}_{5}$. Similarly, all the fault conditions in $\mathrm{FG}_{6}$ have their counterparts in $\mathrm{FG}_{7}$ in view of producing the same fault signature in current. Due to this similarity and complexity, the implementation of a reliable faulty switch localization scheme is a challenging task.

Table 1 summarizes the fault conditions giving the same fault signature in current between $\mathrm{FG}_{4}$ and $\mathrm{FG}_{5}$, and between $\mathrm{FG}_{6}$ and $\mathrm{FG}_{7}$, respectively.

Table 1. Fault conditions giving same fault signature between $\mathrm{FG}_{4}$ and $\mathrm{FG}_{5}$, and between $\mathrm{FG}_{6}$ and $\mathrm{FG}_{7}$.

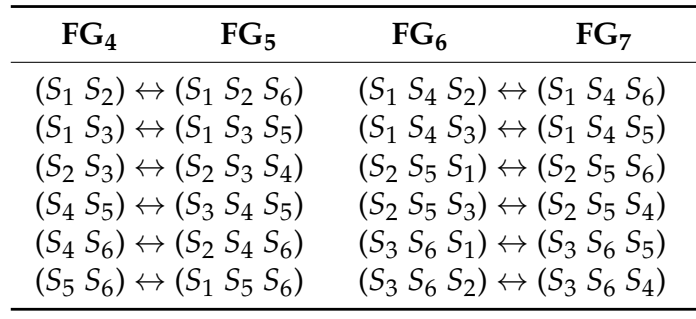

\section{Open-Switch Fault Detection Scheme}

Figure 4 shows the overall control system including the proposed fault diagnosis scheme in a PMSM drive. The entire control system as well as the proposed fault detection and localization schemes is implemented in a DSP-based digital controller within the sampling period. In general, three-phase balanced currents cannot be generated by the PWM inverter under the open-switch faults due to the terminal voltage deviation. As a result, immediate fault detection for an open-switch can be achieved by several conventional methods which use the Park's vectors [14], the average absolute values of normalized currents [19], a voltage-based approach [24], an observer-based technique [32] or an MRAS scheme [35].

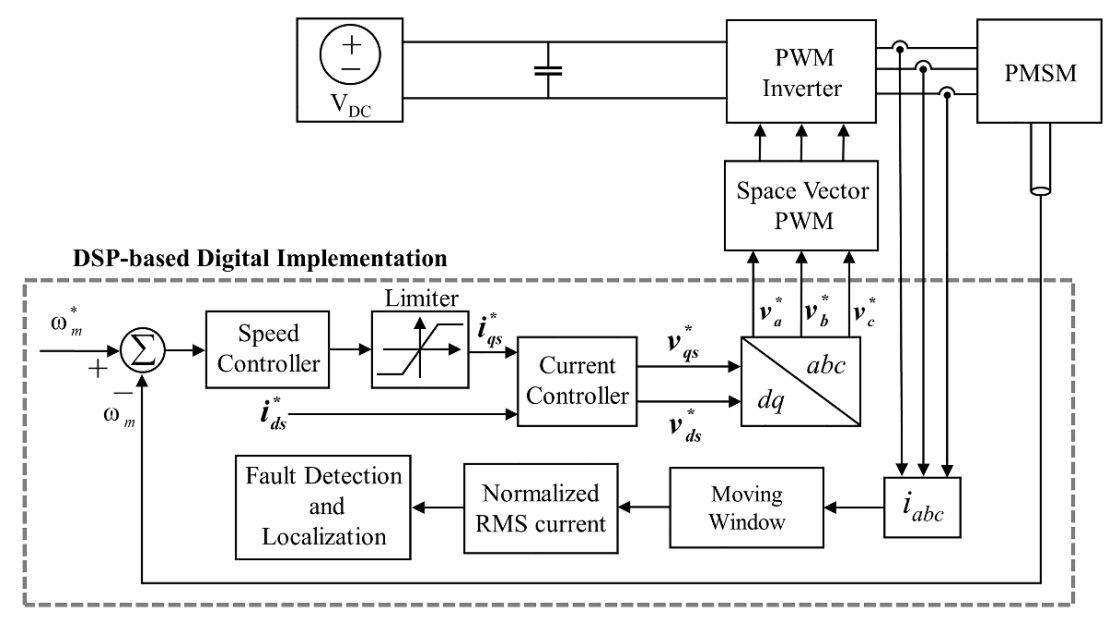

Figure 4. The overall control system including the proposed fault diagnosis scheme in a PMSM drive.

Among them, the open-switch fault detection in this paper is achieved by using the information on the normalized phase currents processed with the moving window [22]. By employing the moving window-based signal processing, the recent periodic data in one window length can be updated at each sampling instant. This scheme is known to be advantageous in view of the fast detection due to rapid update for the diagnosis variable rather than the case that the data is processed only after the entire periodic data is completely acquired. This is a very desirable feature for the diagnosis algorithm 
to install it in a commercial drive system without requiring much computational burden and a large amount of CPU resources.

For the purpose of realizing the detection algorithm independent of the current level and operating conditions, the normalized root-mean-square (RMS) phase currents are employed for the open-switch fault detection as follows:

$$
I_{n, n o r m}=\frac{I_{n, r m s, m w}}{I_{s, m w}}, \text { for } n=a, b, c
$$

where $I_{n, n o r m}$ is the normalized three-phase RMS currents, $I_{s, m w}$ is the magnitude of current calculated by the moving window method, and $I_{n, r m w, m w}$ is three-phase RMS phase currents calculated by the moving window method. For digital implementation, the pulse transfer function of the moving window is expressed as follows:

$$
G(z)=\frac{1}{N} \cdot \frac{1-z^{-N}}{1-z^{-1}}
$$

where $N$ denotes the number of samples in one window length. The normalized three-phase RMS currents $I_{n, n o r m}$ are employed as a fault detection variable and they are continuously compared with the nominal sinusoidal RMS current to detect a fault occurrence. Since the moving window-based currents are employed instead of the conventional entire periodic currents, the fault detection is accomplished instantly as soon as $I_{n, n o r m}$ deviates from the nominal value. When $I_{n, \text { norm }}$ deviates from the nominal value in more than one phase, the fault occurrence is acknowledged by setting the variable $\mathrm{F}_{\text {flag }}$ to one and the operating mode is changed into the proposed fault localization algorithm to investigate the faulty switches.

\section{Proposed Fault Localization Scheme for Simultaneous Open-Switches}

In this section, the proposed fault localization scheme for an inverter open-switch fault is described. The purpose is for the main controller to identify faulty switches reliably without human inference only by observing the fault signature in currents developed by seven fault groups. To localize faulty switches in an expeditious way, the fault group is first identified. According to the analysis in Section 2, positive phase currents flow through the conduction of inverter upper switches $S_{1}, S_{2}$ and $S_{3}$, and negative phase currents through the conduction of inverter lower switches $S_{4}, S_{5}$ and $S_{6}$. Thus, if $N_{n z c}$ is defined as the number of positive and negative current waveforms in each phase within the entire period, the fault group can be basically identified by using $N_{n z c}$, in spite of some exceptional cases. During the normal non-fault condition, the number of positive and negative current waveforms, $N_{n z c}$ becomes 6 because all the positive and negative current waveforms exist in three-phase. However, this value is reduced under open fault conditions depending on the number and position of open-switches. For example, under the open fault in single switch $S_{1}$, which corresponds to $\mathrm{FG}_{1}, N_{n z c}$ becomes 5 because only the positive $a$-phase current is absent.

The fault groups $\mathrm{FG}_{2}$ and $\mathrm{FG}_{3}$ have $N_{n z c}$ equal to 4 because two positive or negative current waveforms are missing. In these cases, by considering that one phase current always remains zero in the fault group $\mathrm{FG}_{2}$ in which the entire switches in one inverter leg have the open faults, these two groups can be easily distinguished by using $I_{n, \text { norm }}$ in Equation (1).

In the fault groups $\mathrm{FG}_{4}$ and $\mathrm{FG}_{5}, N_{n z c}$ is equal to 3 . Even if the number of simultaneous open-switches is two in the fault group $\mathrm{FG}_{4}, N_{n z c}$ is equal to 3 rather than 4 according to the analysis in Figure 2. The fault group $\mathrm{FG}_{4}$ has two open-switches either only in the upper leg or only in the lower leg. Since two open-switches in the upper leg prevent negative current in the other phase and two open-switches in the lower leg prevent positive current in the other phase, $N_{n z c}$ becomes 3 in the fault group $\mathrm{FG}_{4}$. As explained in Figure 2 and Table 1, two fault groups $\mathrm{FG}_{4}$ and $\mathrm{FG}_{5}$ provide exactly the same fault signature in view of three-phase current waveforms. Thus, the exact fault group identification and faulty switch localization are not possible by using only the conventional methods. To overcome this limitation, this paper introduces a free-wheeling mode detection for the purpose of distinguishing these two fault groups. 
Due to the similar analysis, the fault groups $\mathrm{FG}_{6}$ and $\mathrm{FG}_{7}$ have $N_{n z c}$ equal to 2. Even if the number of simultaneous open-switches is three for both the groups, $N_{n z c}$ becomes 2 rather than 3 according to the analysis in Figure 3. These two groups have the open fault in the entire switches of one-phase inverter leg with one additional switch in upper or lower side. Definitely, entire open-switches of one-phase inverter leg yield zero current in that phase. In addition to that, one additional upper open-switch prevents negative current in other phase, and vice versa. As explained in Figure 3 and Table 1, two fault groups $\mathrm{FG}_{6}$ and $\mathrm{FG}_{7}$ provide exactly the same fault signature in view of three-phase current waveforms. Similarly, a free-wheeling mode detection is employed to distinguish these two fault groups. Table 2 summarizes the identification of the fault group in the proposed localization scheme by using the number of positive and negative current waveforms. To identify the fault group, the phase-current information processed with the moving window is employed. As a result, the diagnosis variables are updated at each sampling instant to constitute the recently acquired periodic data in one window length. This permits a rapid update on the diagnosis variables as compared with the method processing the current data only after the entire periodic data is acquired.

Table 2. Identification of fault group by the number of positive and negative current waveforms.

\begin{tabular}{lll}
\hline Conditions & Fault Group & Detailed Conditions \\
\hline If $N_{N Z C}=5$ & Then $\mathrm{FG}_{1}$ & \\
\hline If $N_{N Z C}=4$ & $\begin{array}{l}\text { Then } \mathrm{FG}_{2} \\
\text { Then } \mathrm{FG}_{3}\end{array}$ & $\begin{array}{l}\text { If }\left(I_{a, n o r m}=0\right) \text { or }\left(I_{b, \text { norm }}=0\right) \text { or }\left(I_{c, n o r m}=0\right) \\
\text { Otherwise }\end{array}$ \\
\hline If $N_{N Z C}=3$ & Then $\mathrm{FG}_{4}$ or $\mathrm{FG}_{5}$ & Further identification by free-wheeling mode detection \\
\hline If $N_{N Z C}=2$ & Then $\mathrm{FG}_{6}$ or $\mathrm{FG}_{7}$ & Further identification by free-wheeling mode detection \\
\hline
\end{tabular}

Once the fault group is identified, the faulty switches are detected by using the fault signature developed by each group. In the fault group $\mathrm{FG}_{1}$, the identification of faulty switch can be easily accomplished by finding absent positive or negative current in each phase. For example, under the open-switch fault in $S_{1}$, positive $a$-phase current is absent. Figure 5 shows the detection of faulty switch in $\mathrm{FG}_{1}$, where $i_{a, a v g}, i_{b, a v g}$, and $i_{c, a v g}$ denote three-phase average currents, respectively.

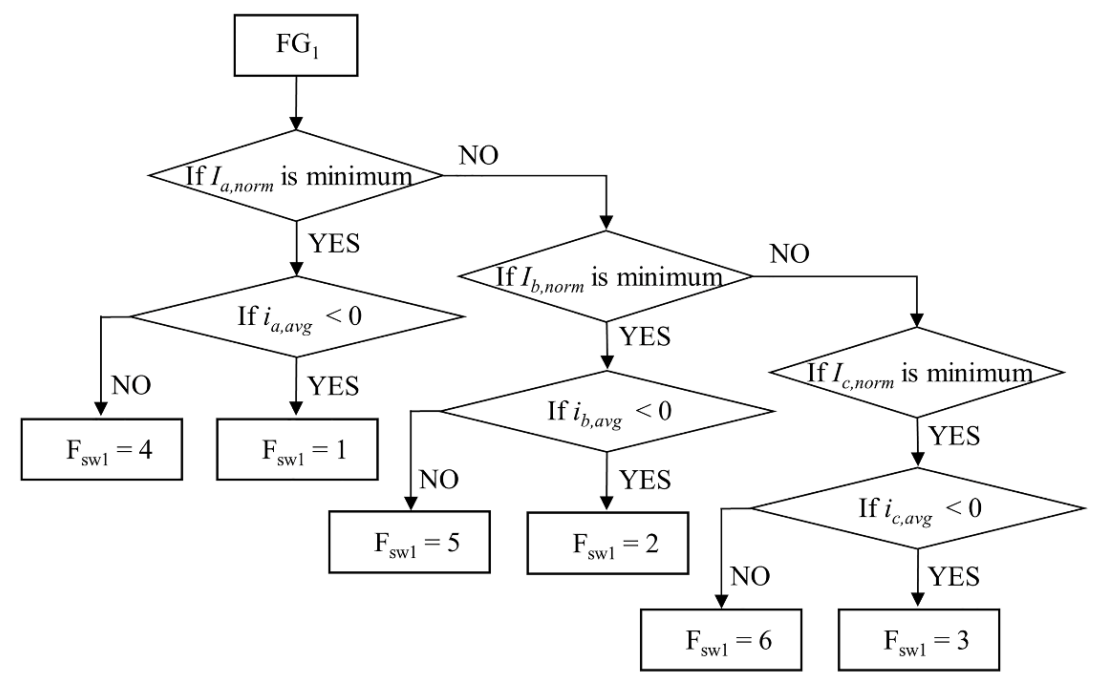

Figure 5. Detection of faulty switch in $\mathrm{FG}_{1}$.

In the fault group $\mathrm{FG}_{2}$, two faulty switches are effectively detected by finding the phase in which the normalized RMS current $I_{n, n o r m}$ for $n=a, b, c$ is minimum. This is due to the fact that one phase current always remains zero in this fault group since the entire switches in one inverter leg have 
the open-switch faults. For example, under the simultaneous open-switch faults in $S_{1}$ and $S_{4}, I_{a, n o r m}$ remains zero because both the positive and negative $a$-phase currents are absent. Figure 6 shows the detection of two simultaneous faulty switches in $\mathrm{FG}_{2}$.

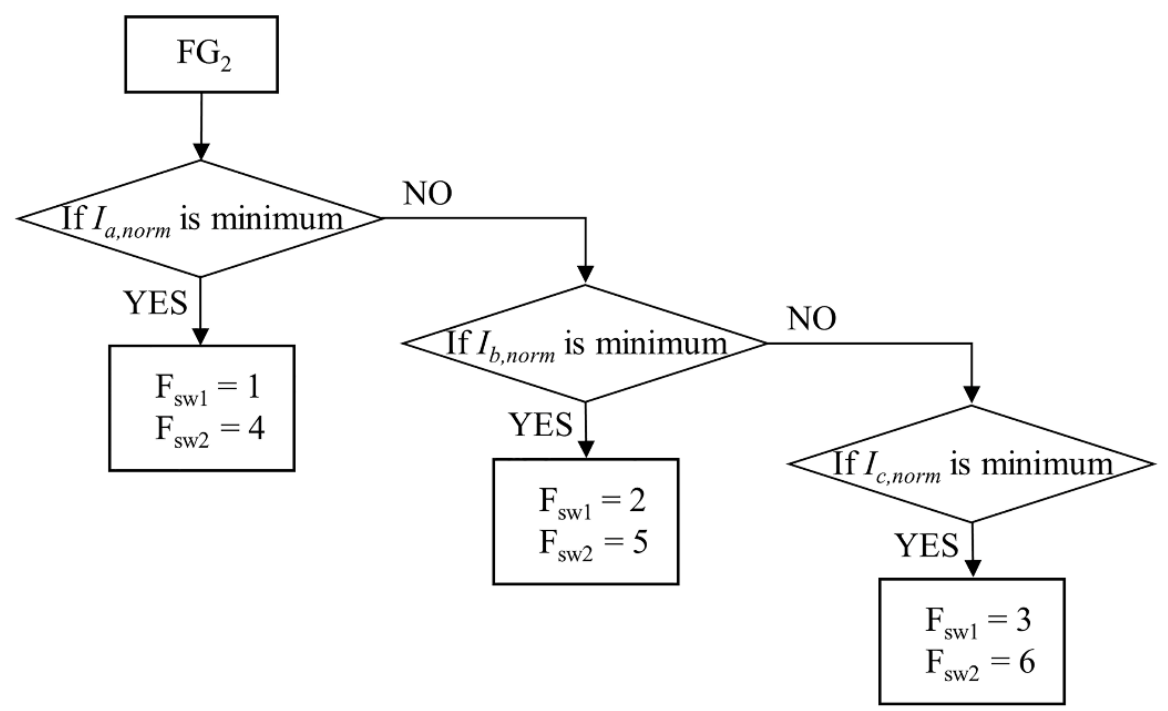

Figure 6. Detection of two simultaneous faulty switches in $\mathrm{FG}_{2}$.

In the fault group $\mathrm{FG}_{3}$, the identification of two faulty switches can be achieved by finding two absent positive and negative currents in three-phase. Because $N_{n z c}$ is equal to 4 in this fault group, two absent positive and negative current waveforms provide the information on two faulty switches. For example, under the simultaneous open-switch faults in $S_{1}$ and $S_{5}$, two absent current waveforms are positive $a$-phase current and negative $b$-phase current. Table 3 shows the detection of two simultaneous faulty switches in $\mathrm{FG}_{3}$, in which $I_{n+}$ and $I_{n-}($ for $n=a, b, c)$ are defined as positive and negative current waveforms in each phase, respectively.

Table 3. Detection of two simultaneous faulty switches in $\mathrm{FG}_{3}$.

\begin{tabular}{cc}
\hline Conditions & Fault Switches \\
\hline If $i_{a+}$ and $i_{a-}$ do not exist & Then $\mathrm{F}_{\mathrm{sw} 1}=S_{1}, \mathrm{~F}_{\mathrm{sw} 2}=S_{5}$ \\
If $i_{a+}$ and $c_{a-}$ do not exist & Then $\mathrm{F}_{\mathrm{sw} 1}=S_{1}, \mathrm{~F}_{\mathrm{sw} 2}=S_{6}$ \\
If $i_{b+}$ and $i_{a-}$ do not exist & Then $\mathrm{F}_{\mathrm{sw} 1}=S_{2}, \mathrm{~F}_{\mathrm{sw} 2}=S_{4}$ \\
If $i_{b+}$ and $i_{c-}$ do not exist & Then $\mathrm{F}_{\mathrm{sw} 1}=S_{2}, \mathrm{~F}_{\mathrm{sw} 2}=S_{6}$ \\
If $i_{c+}$ and $i_{a-}$ do not exist & Then $\mathrm{F}_{\mathrm{sw} 1}=S_{3}, \mathrm{~F}_{\mathrm{sw} 2}=S_{4}$ \\
If $i_{c+}$ and $i_{b-}$ do not exist & Then $\mathrm{F}_{\mathrm{sw} 1}=S_{3}, \mathrm{~F}_{\mathrm{sw} 2}=S_{5}$ \\
\hline
\end{tabular}

The fault groups $\mathrm{FG}_{4}$ and $\mathrm{FG}_{5}$ can be effectively separated from the other remaining groups by using $N_{n z c}$ equal to 3 . By finding three absent positive and negative currents among three-phase currents, these groups are easily distinguished from other groups. However, all the fault conditions in $\mathrm{FG}_{4}$ have their counterparts in $\mathrm{FG}_{5}$ in view of giving exactly the same fault signature in three-phase current waveforms according to the analysis in Figure 2 and Table 1. Table 4 shows the detection of simultaneous faulty switches in $\mathrm{FG}_{4}$ and $\mathrm{FG}_{5}$. Under the open faults either in two upper or two lower switches, the fault signature is irrespective of the fault in the opposite switch of the remaining phase, as is observed in the case for the simultaneous open-switch faults in $S_{1}$ and $S_{2}$ of $\mathrm{FG}_{4}$, and the simultaneous open-switch faults in $S_{1}, S_{2}$ and $S_{6}$ of $\mathrm{FG}_{5}$ as in Figure 2. For example, when positive $a$-phase, negative $b$-phase, and negative $c$-phase currents are missing as in the first low of Table 4 , only the simultaneous open-switch faults in $S_{5}$ and $S_{6}$ are distinct. It is not sure whether the open-switch fault occurs in $S_{1}$ or not. 
Table 4. Detection of simultaneous faulty switches in $\mathrm{FG}_{4}$ and $\mathrm{FG}_{5}$.

\begin{tabular}{|c|c|c|c|}
\hline Conditions & Fault Switches & Free-Wheeling Mode Test & Final Detection Results \\
\hline If $i_{a+}, i_{b-}$ and $i_{c-}$ do not exist & Then $\begin{aligned} \mathrm{F}_{\mathrm{sw} 1} & =S_{5} \\
\mathrm{~F}_{\mathrm{sw} 2} & =S_{6}\end{aligned}$ & $\rightarrow$ Free-wheeling mode test for $S_{1}$ & $\begin{array}{l}\mathrm{FG}_{4}, \mathrm{~F}_{\mathrm{sw} 3}=\text { None } \\
\mathrm{FG}_{5}, \mathrm{~F}_{\mathrm{sw} 3}=S_{1}\end{array}$ \\
\hline If $i_{a-}, i_{b+}$ and $i_{c-}$ do not exist & Then $\begin{aligned} \mathrm{F}_{\mathrm{sw} 1} & =S_{4} \\
\mathrm{~F}_{\mathrm{sw} 2} & =S_{6}\end{aligned}$ & $\rightarrow$ Free-wheeling mode test for $S_{2}$ & $\begin{array}{l}\mathrm{FG}_{4}, \mathrm{~F}_{\mathrm{sw} 3}=\text { None } \\
\mathrm{FG}_{5}, \mathrm{~F}_{\mathrm{sw} 3}=S_{2}\end{array}$ \\
\hline If $i_{a-}, i_{b-}$ and $i_{c+}$ do not exist & Then $\begin{aligned} \mathrm{F}_{\mathrm{sw} 1} & =S_{4} \\
\mathrm{~F}_{\mathrm{sw} 2} & =S_{5}\end{aligned}$ & $\rightarrow$ Free-wheeling mode test for $S_{3}$ & $\begin{array}{l}\mathrm{FG}_{4}, \mathrm{~F}_{\mathrm{sw} 3}=\text { None } \\
\mathrm{FG}_{5}, \mathrm{~F}_{\mathrm{sw} 3}=S_{3}\end{array}$ \\
\hline If $i_{a-}, i_{b+}$ and $i_{c+}$ do not exist & Then $\begin{aligned} \mathrm{F}_{\mathrm{sw} 1} & =S_{2} \\
\mathrm{~F}_{\mathrm{sw} 2} & =S_{3}\end{aligned}$ & $\rightarrow$ Free-wheeling mode test for $S_{4}$ & $\begin{array}{l}\mathrm{FG}_{4}, \mathrm{~F}_{\mathrm{sw} 3}=\text { None } \\
\mathrm{FG}_{5}, \mathrm{~F}_{\mathrm{sw} 3}=S_{4}\end{array}$ \\
\hline If $i_{a+} i_{b-}$ and $i_{c+}$ do not exist & Then $\begin{aligned} \mathrm{F}_{\mathrm{sw} 1} & =S_{1} \\
\mathrm{~F}_{\mathrm{sw} 2} & =S_{3}\end{aligned}$ & $\rightarrow$ Free-wheeling mode test for $S_{5}$ & $\begin{array}{l}\mathrm{FG}_{4}, \mathrm{~F}_{\mathrm{sw} 3}=\text { None } \\
\mathrm{FG}_{5}, \mathrm{~F}_{\mathrm{sw} 3}=S_{5}\end{array}$ \\
\hline If $i_{a+}, i_{b+}$ and $i_{c-}$ do not exist & Then $\begin{aligned} \mathrm{F}_{\mathrm{sw} 1} & =S_{1} \\
\mathrm{~F}_{\mathrm{sw} 2} & =S_{2}\end{aligned}$ & $\rightarrow$ Free-wheeling mode test for $S_{6}$ & $\begin{array}{l}\mathrm{FG}_{4}, \mathrm{~F}_{\mathrm{sw} 3}=\text { None } \\
\mathrm{FG}_{5}, \mathrm{~F}_{\mathrm{sw} 3}=S_{6}\end{array}$ \\
\hline
\end{tabular}

To further distinguish the fault groups $\mathrm{FG}_{4}$ and $\mathrm{FG}_{5}$ as well as to detect all faulty switches, a free-wheeling mode detection is employed, which is composed of the positive free-wheeling mode detection and negative free-wheeling mode detection carried out in sequence. While the inverter upper switches $S_{1}, S_{2}$ and $S_{3}$ are forced to turn on to investigate faulty switches during the test period of the positive free-wheeling mode detection, the inverter lower switches $S_{4}, S_{5}$ and $S_{6}$ are forced to turn on during that of the negative free-wheeling mode detection. As the free-wheeling mode in inverter decelerates the machine, the free-wheeling mode detection is only applicable to the condition that the machine is rotating with a sufficient speed. In spite of this limitation, it can be a reliable method to detect an open-switch fault for such condition that the faulty switches cannot be clearly detected by using the powering mode.

Figure 7 shows the concept of the free-wheeling mode detection. If the kinetic energy of the machine is sufficient during the free-wheeling mode, the currents flow through the path composed of the switches and diodes, decelerating the machine velocity. Figure 7a shows three-phase current waveforms during the positive free-wheeling mode under non-fault condition. For the case in the first low of Table 4, only the simultaneous open-switch faults in $S_{5}$ and $S_{6}$ are clear and the open-switch fault in $S_{1}$ is not sure. Figure $7 \mathrm{~b}$ shows the case that the positive free-wheeling mode is applied to detect the open-switch fault in $S_{1}$, where the inverter upper switches $S_{1}, S_{2}$ and $S_{3}$ are forced to turn on. Whereas negative $a$-phase free-wheeling current can flow through diode $D_{1}$, positive $a$-phase free-wheeling current can flow only when $S_{1}$ does not have the open-switch fault. Thus, by investigating the existence of positive $a$-phase free-wheeling current, the open-switch fault in $S_{1}$ can be determined. As a result, even if both the simultaneous open-switch faults in $S_{5}$ and $S_{6}$ of $F_{4}$ and those in $S_{1}, S_{5}$ and $S_{6}$ of FG 5 develop the same fault signature, the exact fault group and the faulty switch location can be identified by using the positive free-wheeling mode detection.

For the case in the last row of Table 4, only the simultaneous open-switch faults in $S_{1}$ and $S_{2}$ are clear and the open-switch fault in $S_{6}$ is doubtful. Figure $7 \mathrm{c}$ shows the application of the negative free-wheeling mode to detect the open-switch fault in $S_{6}$ for this case, where the inverter lower switches $S_{4}, S_{5}$ and $S_{6}$ are forced to turn on. With the negative free-wheeling mode, positive $c$-phase free-wheeling current flows through diode $D_{6}$. Thus, by investigating the existence of negative $c$-phase free-wheeling current, the open-switch fault in $S_{6}$ can be determined, which achieves the exact fault localization.

The fault groups $\mathrm{FG}_{6}$ and $\mathrm{FG}_{7}$ can be similarly separated with the other remaining groups by using the information on $N_{n z c}$ equal to 2, which means that four positive or negative currents among three-phase currents are absent. Similar to the case of the fault groups $F_{4}$ and $F_{5}$, all the fault conditions in $\mathrm{FG}_{6}$ have their counterparts in $\mathrm{FG}_{7}$ in view of giving exactly the same fault signature in three-phase current waveforms according to the analysis in Figure 2 and Table 1. Table 5 shows 
the detection of three simultaneous faulty switches in $\mathrm{FG}_{6}$ and $\mathrm{FG}_{7}$. As shown in the first low of Table 5, when the entire switches of $a$-phase inverter leg have open faults, the fault signature is the same irrespective of one additional open-switch either in $S_{2}$ or $S_{6}$. Thus, when the entire $a$-phase, positive $b$-phase, and negative $c$-phase currents are missing as in the first low of Table 5, only the simultaneous open-switch faults in $S_{1}$ and $S_{4}$ are clear. It is not sure where the additional open-switch fault occurs in $S_{2}$ or $S_{6}$. However, even in this case, the remaining additional open-switch fault can be effectively detected by using the similar way described in Figure 7. During the positive free-wheeling mode detection, the open-switch fault in $S_{2}$ can be determined. If positive $b$-phase free-wheeling current exists, $S_{2}$ does not have the open-switch fault, and vice versa. Similarly, the open-switch fault in $S_{6}$ can be determined during the negative free-wheeling mode detection. If negative $c$-phase free-wheeling current exists, $S_{6}$ does not have the open-switch fault, and vice versa. As a result, all the fault conditions in the fault groups $\mathrm{FG}_{6}$ and $\mathrm{FG}_{7}$ can be effectively identified by the proposed fault localization algorithm.

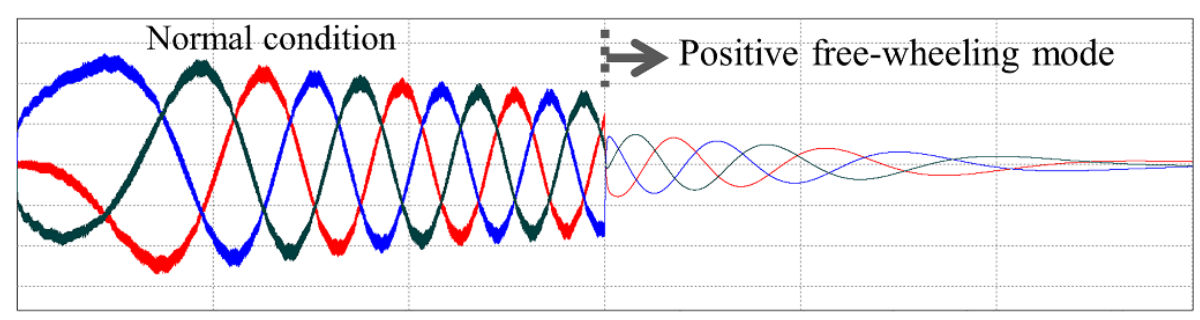

(a)

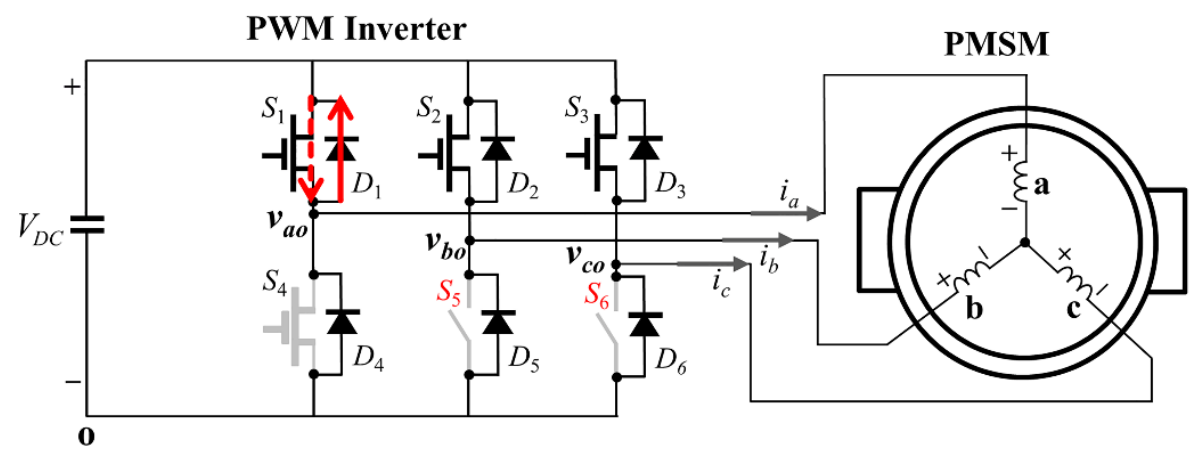

(b)

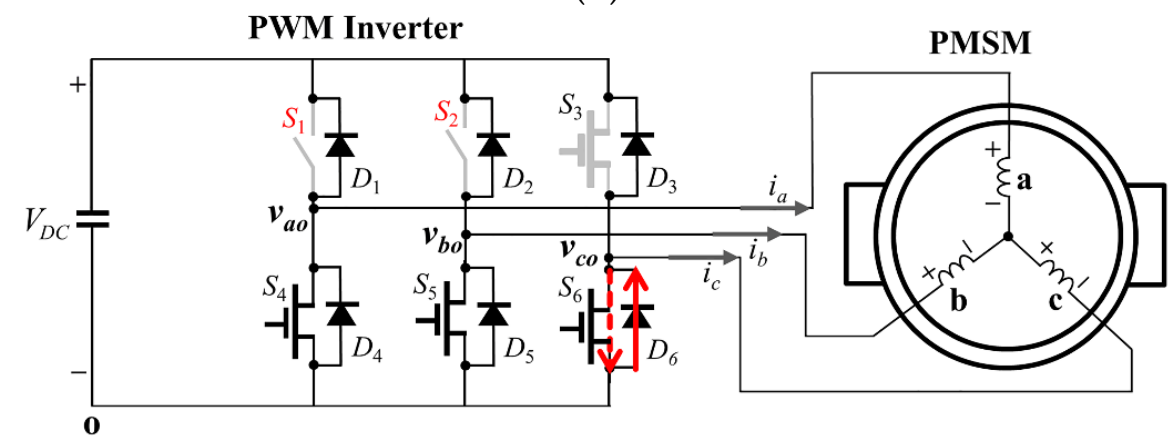

(c)

Figure 7. Free-wheeling mode detection to classify the fault groups $\mathrm{FG}_{4}$ and $\mathrm{FG}_{5}$. (a) Three-phase current waveforms during the positive free-wheeling mode under non-fault condition; (b) Positive free-wheeling mode to detect the open-switch fault in $S_{1}$; (c) Negative free-wheeling mode to detect the open-switch fault in $S_{6}$. 
Table 5. Detection of three simultaneous faulty switches in $\mathrm{FG}_{6}$ and $\mathrm{FG}_{7}$.

\begin{tabular}{|c|c|c|c|}
\hline Conditions & Fault Switches & Free-Wheeling Mode Test & Final Detection Results \\
\hline If $i_{a}, i_{b+}$ and $i_{c-}$ do not exist & Then $\begin{aligned} \mathrm{F}_{\mathrm{Sw} 1} & =S_{1} \\
\mathrm{~F}_{\mathrm{sw} 2} & =S_{4}\end{aligned}$ & $\rightarrow$ Free-wheeling mode test for $S_{2}$ and $S_{6}$ & $\begin{array}{l}\mathrm{FG}_{6}, \mathrm{~F}_{\mathrm{sw} 3}=S_{2} \\
\mathrm{FG}_{7}, \mathrm{~F}_{\mathrm{sw} 3}=S_{6}\end{array}$ \\
\hline If $i_{a}, i_{b-}$ and $i_{c+}$ do not exist & Then $\begin{aligned} \mathrm{F}_{\mathrm{sw} 1} & =S_{1} \\
\mathrm{~F}_{\mathrm{sw} 2} & =S_{4}\end{aligned}$ & $\rightarrow$ Free-wheeling mode test for $S_{3}$ and $S_{5}$ & $\begin{array}{l}\mathrm{FG}_{6}, \mathrm{~F}_{\mathrm{sw} 3}=S_{3} \\
\mathrm{FG}_{7}, \mathrm{~F}_{\mathrm{sw} 3}=S_{5}\end{array}$ \\
\hline If $i_{b}, i_{a+}$ and $i_{c-}$ do not exist & Then $\begin{aligned} \mathrm{F}_{\mathrm{sw} 1} & =S_{2} \\
\mathrm{~F}_{\mathrm{sw} 2} & =S_{5}\end{aligned}$ & $\rightarrow$ Free-wheeling mode test for $S_{1}$ and $S_{6}$ & $\begin{array}{l}\mathrm{FG}_{6}, \mathrm{~F}_{\mathrm{sw} 3}=S_{1} \\
\mathrm{FG}_{7}, \mathrm{~F}_{\mathrm{sw} 3}=S_{6}\end{array}$ \\
\hline If $i_{b}, i_{a-}$ and $i_{c+}$ do not exist & Then $\begin{aligned} \mathrm{F}_{\mathrm{sw} 1} & =S_{2} \\
\mathrm{~F}_{\mathrm{sw} 2} & =S_{5}\end{aligned}$ & $\rightarrow$ Free-wheeling mode test for $S_{3}$ and $S_{4}$ & $\begin{array}{l}\mathrm{FG}_{6}, \mathrm{~F}_{\mathrm{sw} 3}=S_{3} \\
\mathrm{FG}_{7}, \mathrm{~F}_{\mathrm{sw} 3}=S_{4}\end{array}$ \\
\hline If $i_{c}, i_{a+}$ and $i_{b-}$ do not exist & Then $\begin{aligned} \mathrm{F}_{\mathrm{sw} 1} & =S_{3} \\
\mathrm{~F}_{\mathrm{sw} 2} & =S_{6}\end{aligned}$ & $\rightarrow$ Free-wheeling mode test for $S_{1}$ and $S_{5}$ & $\begin{aligned} & \mathrm{FG}_{6}, \mathrm{~F}_{\mathrm{sw} 3}=S_{1} \\
& \mathrm{FG}_{7}, \mathrm{~F}_{\mathrm{sw} 3}=S_{5}\end{aligned}$ \\
\hline If $i_{c}, i_{a-}$ and $i_{b+}$ do not exist & Then $\begin{aligned} \mathrm{F}_{\mathrm{sw} 1} & =S_{3} \\
\mathrm{~F}_{\mathrm{sw} 2} & =S_{6}\end{aligned}$ & $\rightarrow$ Free-wheeling mode test for $S_{2}$ and $S_{4}$ & $\begin{aligned} & \mathrm{FG}_{6}, \mathrm{~F}_{\mathrm{sw} 3}=S_{2} \\
& \mathrm{FG}_{7}, \mathrm{~F}_{\mathrm{sw} 3}=S_{4}\end{aligned}$ \\
\hline
\end{tabular}

\section{Experimental Results}

To verify the feasibility and practical usefulness of the proposed on-line fault localization scheme in a PWM inverter-fed PMSM drive system, the experimental results are presented under various open fault conditions. The overall configuration of the experimental system is shown in Figure 8. The experimental system is composed of a PWM inverter, a PMSM, and a DSP-based digital controller. The entire control and diagnosis algorithm are implemented on TMS320F28335 32-bit floating-point DSP [37]. Inverter phase currents are measured by the Hall sensors and fed to the DSP using the internal 12-bit A/D converter with the resolution of $40 / 2^{11}$ A. The sampling period is selected as $100 \mu$ s to implement the entire control and diagnosis algorithm. The intelligent power module (IPM) is employed for a PWM inverter and the inverter gate signals are generated through internal 16-bit PWM port in DSP with a switching frequency of $10 \mathrm{kHz}$.

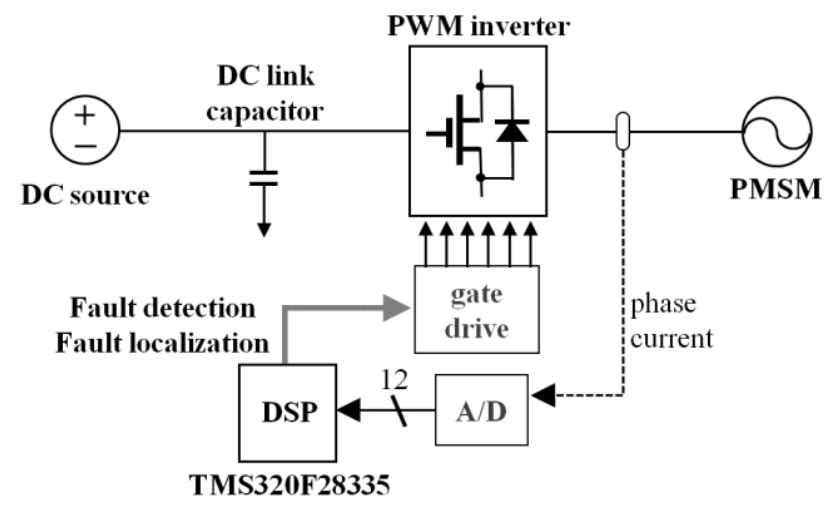

Figure 8. Overall configuration of the experimental system.

Figure 9 shows a photograph for the experimental test setup consisting of a PMSM, permanent magnet DC (PMDC) generator, and electric load. The specifications and parameters of the PMSM are listed in Table 6.

Figure 10 shows the experimental results for the proposed fault detection and faulty switch localization under the open-switch fault in $S_{1}$ of $\mathrm{FG}_{1}$. In this figure, the first waveform indicates the instant of fault occurrence. The second waveforms in Figure 10 represent three-phase current responses $i_{a}, i_{b}$ and $i_{c}$. As can be observed, positive $a$-phase current does not exist due to the open-switch fault in $S_{1}$, which results in $N_{n z c}$ equal to 5 . As the normalized three-phase RMS currents $I_{n, n o r m}$ used for a fault detection variable deviate from the nominal value, the fault occurrence is acknowledged instantly by setting the variable $\mathrm{F}_{\text {flag }}$ to 1 as shown in the third waveform in Figure 10. Then, the diagnosis algorithm 
is changed into the proposed fault localization algorithm to find the fault locations. The first step is to determine the fault group by using the number of positive and negative current waveforms, $N_{n z c}$ in Table 2. The fourth waveform in Figure 10 shows the detection result for the fault group (FG) which the fault belongs to. The next step is to investigate the faulty switch in $\mathrm{FG}_{1}$ by using Figure 5 . The last waveforms in Figure 10 show the values of the faulty switch. In these figures, the values of one through seven are designated to denote the fault group $\mathrm{FG}_{1}$ through $\mathrm{FG}_{7}$, and $\mathrm{F}_{\mathrm{sw} 1}, \mathrm{~F}_{\mathrm{sw} 2}$, and $\mathrm{F}_{\mathrm{sw} 3}$ are employed to denote three faulty switches, respectively. After small transient period, the proposed fault localization scheme determines $\mathrm{FG}=1, \mathrm{~F}_{\mathrm{sw} 1}=1, \mathrm{~F}_{\mathrm{sw} 2}=0$, and $\mathrm{F}_{\mathrm{sw} 3}=0$, which indicates that the fault belongs to $\mathrm{FG}_{1}$ and the open-switch fault location is $S_{1}$.

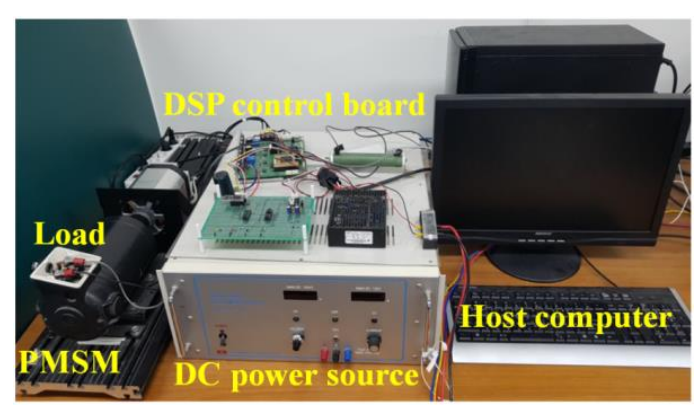

Figure 9. Experimental test setup.

Table 6. Specifications and parameters of a PMSM.

\begin{tabular}{ccc}
\hline Parameters & Value & Units \\
\hline Rated power & 400 & $\mathrm{~W}$ \\
Rated speed & 3000 & $\mathrm{rpm}$ \\
Number of poles & 6 & - \\
Magnetic flux & 0.017 & $\mathrm{~Wb}$ \\
Stator resistance & 0.5 & $\Omega$ \\
$q$-axis stator inductance & 0.254 & $\mathrm{mH}$ \\
-axis stator inductance & 0.157 & $\mathrm{mH}$ \\
Moment of inertia & 0.1 & $\mathrm{~kg} \cdot \mathrm{m}^{2}$ \\
\hline
\end{tabular}

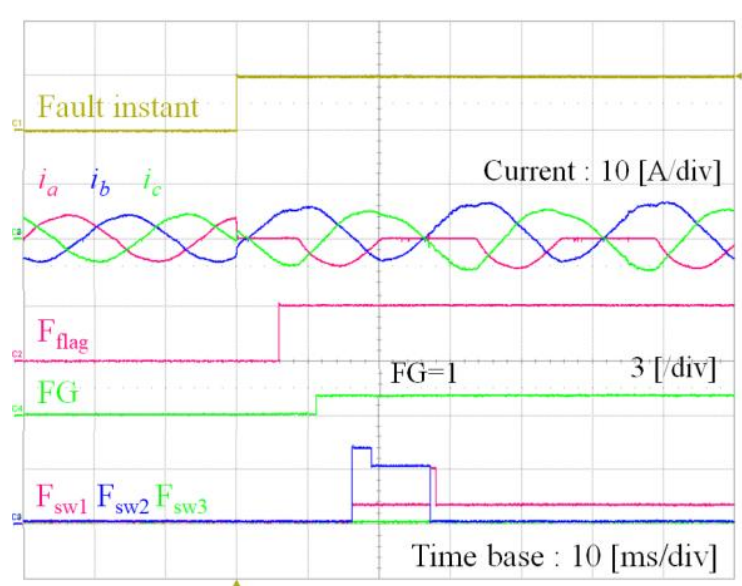

Figure 10. Experimental results for the proposed fault detection and localization under the open-switch fault in $S_{1}$ of $\mathrm{FG}_{1}$.

Figure 11 shows the experimental results for the proposed fault detection and faulty switch localization under the simultaneous open-switch faults in $S_{1}$ and $S_{4}$ of $\mathrm{FG}_{2}$. Similarly, the waveforms 
represent the instant of fault occurrence, three-phase currents responses, the variable $\mathrm{F}_{\text {flag, }}$, the detected result for $F G$, and three faulty switches $F_{\mathrm{sw} 1}, \mathrm{~F}_{\mathrm{sw} 2}$ and $\mathrm{F}_{\mathrm{sw} 3}$ respectively, from the top. As can be observed in three-phase currents, entire $a$-phase current $i_{a}$ is very close to zero due to the open-switch faults in $S_{1}$ and $S_{4}$. As soon as the detection variable, $I_{a, n o r m}$ deviates from the nominal value, the fault occurrence is acknowledged. In addition, the fault group is determined as $F_{2}$ by using $N_{n z c}=4$ and $I_{a, \text { norm }}=0$ in Table 2 . Then, the proposed fault diagnosis algorithm investigates the faulty switches by using Figure 6. The final detection results are $\mathrm{FG}=2, \mathrm{~F}_{\mathrm{sw} 1}=1, \mathrm{~F}_{\mathrm{sw} 2}=4$, and $\mathrm{F}_{\mathrm{sw} 3}=0$, which indicates that the fault belongs to $\mathrm{FG}_{2}$ and the open-switch faults occur in $S_{1}$ and $S_{4}$ as shown in Figure 11.

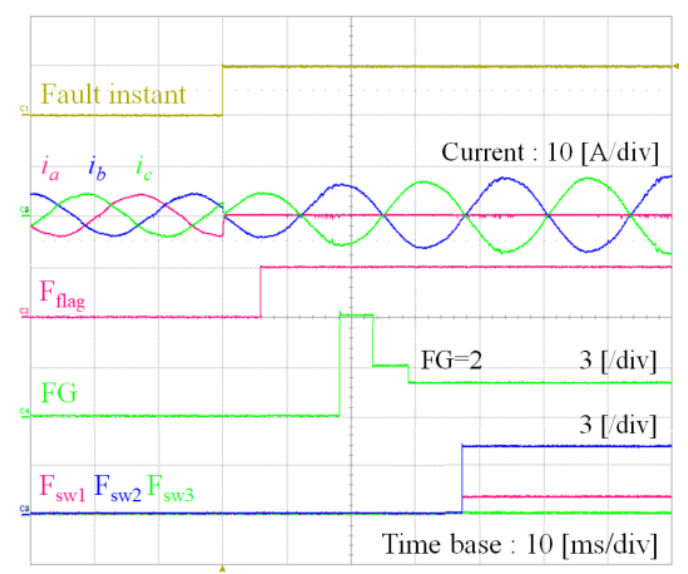

Figure 11. Experimental results for the proposed fault detection and localization under the simultaneous open-switch faults in $S_{1}$ and $S_{4}$ of $\mathrm{FG}_{2}$.

Figure 12 shows the experimental results for the proposed fault detection and faulty switch localization under the simultaneous open-switch faults in $S_{1}$ and $S_{5}$ of $\mathrm{FG}_{3}$. As is obvious in three-phase currents, $a$-phase positive current and $b$-phase negative current do not exist, which yields $N_{n z c}=4$. Following the procedures in Tables 2 and 3 , the proposed fault diagnosis algorithm determines $F G=3$, $\mathrm{F}_{\mathrm{sw} 1}=1, \mathrm{~F}_{\mathrm{sw} 2}=5$, and $\mathrm{F}_{\mathrm{sw} 3}=0$ as the final detection results, which indicates that the fault belongs to $\mathrm{FG}_{3}$ and the open-switch faults occur in $S_{1}$ and $S_{5}$ as shown in Figure 12.

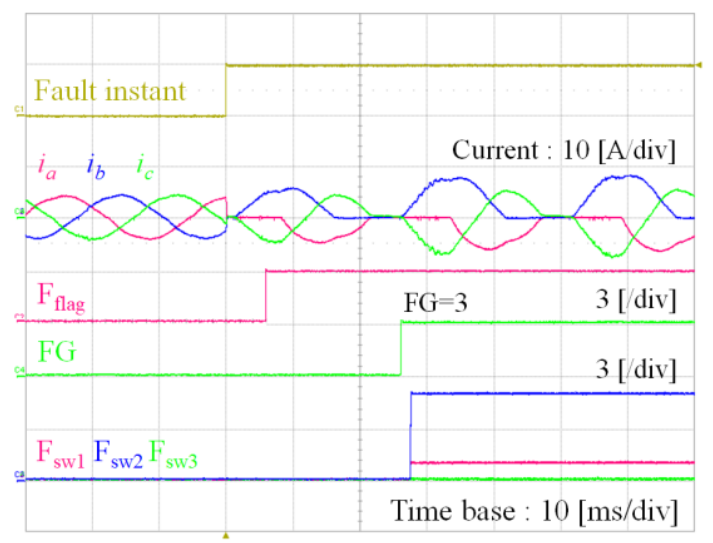

Figure 12. Experimental results for the proposed fault detection and localization under the simultaneous open-switch faults in $S_{1}$ and $S_{5}$ of $\mathrm{FG}_{3}$.

Figure 13 shows the experimental results for the proposed fault detection and faulty switch localization under the simultaneous open-switch faults in $S_{1}$ and $S_{2}$ of $\mathrm{FG}_{4}$. In this fault condition, the number of positive and negative current waveforms, $N_{n z c}$ is equal to 3 because only a-phase 
negative, $b$-phase negative, and $c$-phase positive currents exist as shown in Figure 13a. Following the procedures in Table 2, the fault group is determined as $\mathrm{FG}_{4}$ or $\mathrm{FG}_{5}$. Also, according to Table 4, the simultaneous open-switch faults in $S_{1}$ and $S_{2}$ are clear and the additional open-switch fault in $S_{6}$ is not sure. To detect the remaining additional open-switch fault, the detection by free-wheeling mode test is introduced by using the method described in Figure 7 as shown in Figure 13b. In this case, since the possible location for open-switch is the inverter lower side, the negative free-wheeling mode detection is employed. When the negative free-wheeling mode is applied, the open-switch fault in $S_{6}$ can be detected by investigating negative $c$-phase free-wheeling current as shown in Figure $7 \mathrm{~b}$. It is shown from Figure $13 \mathrm{~b}$ that all the positive and negative free-wheeling currents exist. Thus, it can be concluded that the switch $S_{6}$ does not have the open-switch fault. As a result, the proposed fault diagnosis algorithm determines $\mathrm{FG}=4, \mathrm{~F}_{\mathrm{sw} 1}=1, \mathrm{~F}_{\mathrm{sw} 2}=2$, and $\mathrm{F}_{\mathrm{sw} 3}=0$ as the final detection results, which indicates that the fault belongs to $\mathrm{FG}_{4}$ and the open-switch faults occur in $S_{1}$ and $S_{2}$ as shown in Figure 13.

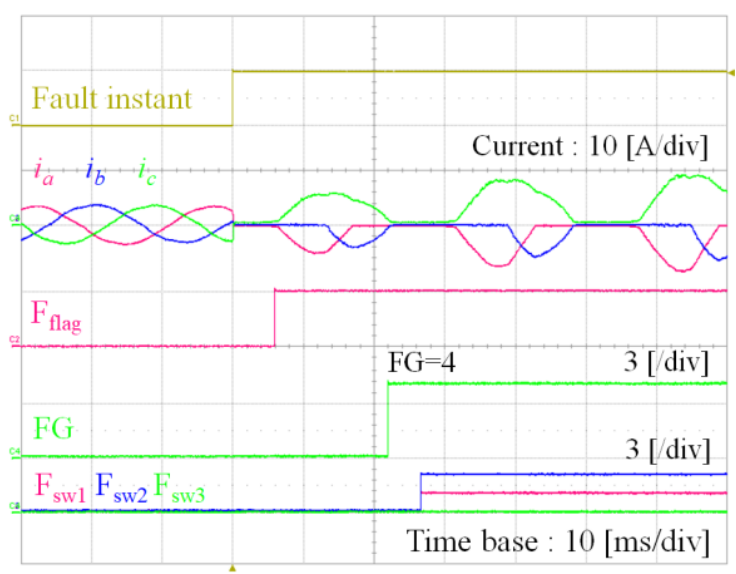

(a)

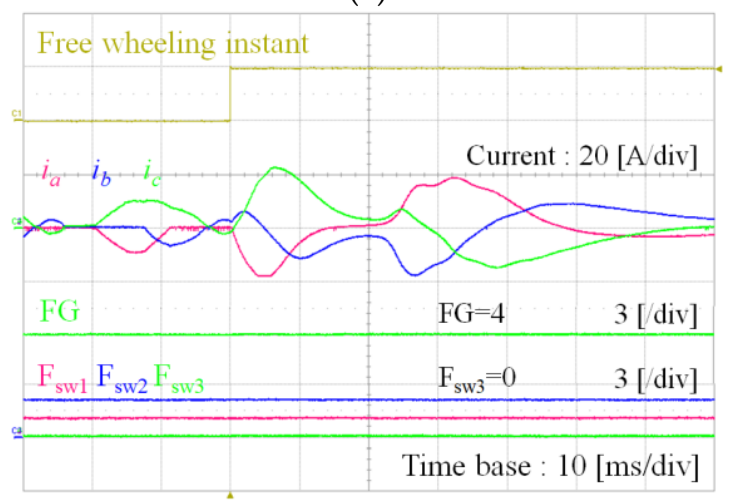

(b)

Figure 13. Experimental results for the proposed fault detection and localization under the simultaneous open-switch faults in $S_{1}$ and $S_{2}$ of $\mathrm{FG}_{4}$. (a) Detection of fault group and faulty switches; (b) Free-wheeling mode detection.

Figure 14 shows the experimental results for the proposed fault detection and faulty switch localization under the simultaneous open-switch faults in $S_{1}, S_{2}$ and $S_{6}$ of $F_{5}$. As shown in the current waveforms in Figures 13a and 14a, this fault condition gives the same fault signature with that of the open-switch faults only in $S_{1}$ and $S_{2}$. Following the procedures in Table 2, the fault group is determined as $\mathrm{FG}_{4}$ or $\mathrm{FG}_{5}$, and the simultaneous open-switch faults in $S_{1}$ and $S_{2}$ are only clear and the additional open-switch fault in $S_{6}$ is not sure according to Table 4 . Similarly, the remaining additional open-switch fault can be effectively detected by negative free-wheeling mode test as shown 
in Figure 14b. It is clearly shown in Figure $14 \mathrm{~b}$ that $c$-phase negative current does not exist during the negative free-wheeling mode test, even though other phases have both positive and negative currents, which implies the open-switch fault in $S_{6}$. Thus, the final detection results of the proposed fault diagnosis algorithm are $\mathrm{FG}=5, \mathrm{~F}_{\mathrm{sw} 1}=1, \mathrm{~F}_{\mathrm{sw} 2}=2$, and $\mathrm{F}_{\mathrm{sw} 3}=6$, which indicates that the fault belongs to $F_{5}$ and the open-switch faults occur in $S_{1}, S_{2}$ and $S_{6}$ as shown in Figure $14 \mathrm{~b}$.

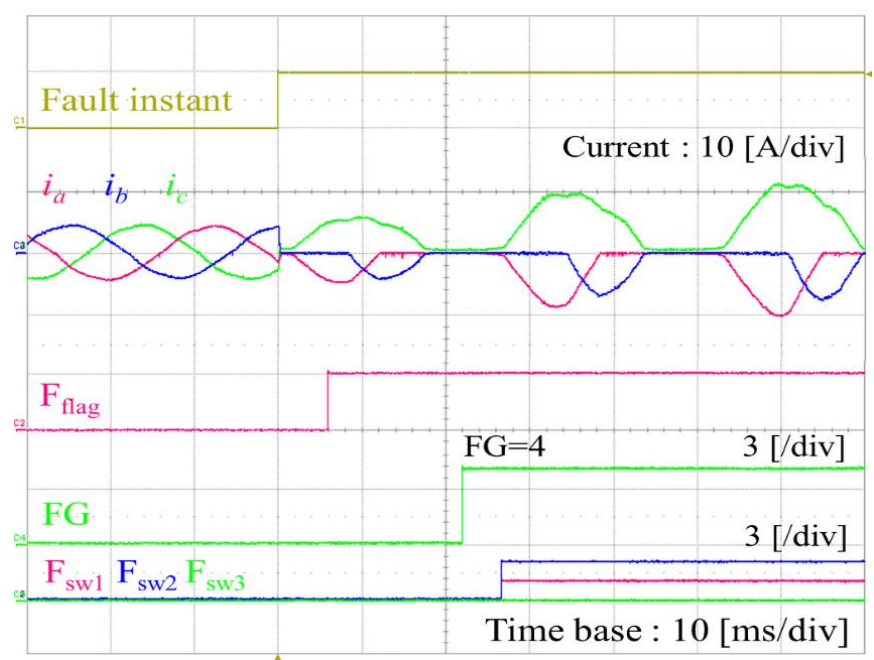

(a)

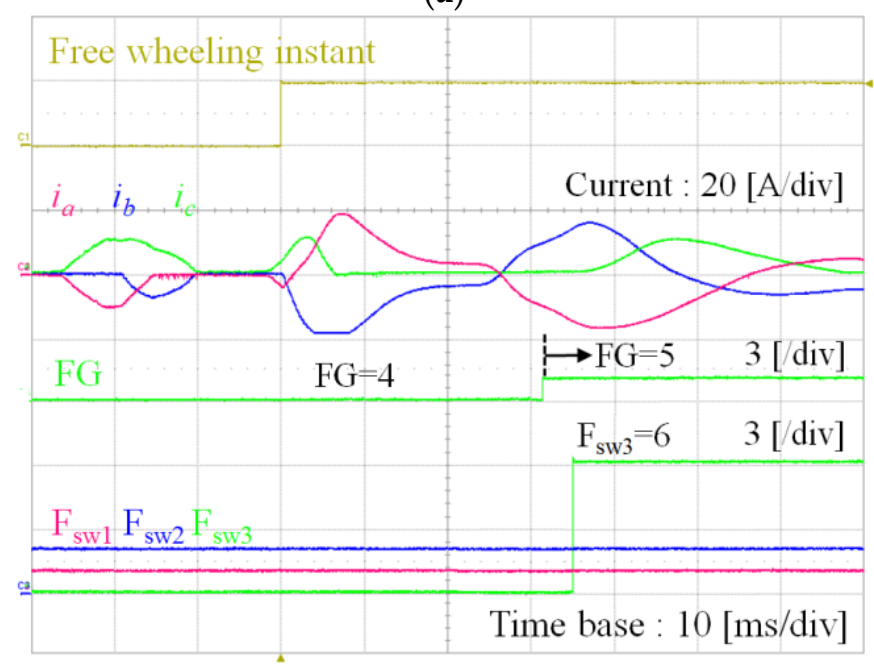

(b)

Figure 14. Experimental results for the proposed fault detection and localization under the simultaneous open-switch faults in $S_{1}, S_{2}$ and $S_{6}$ of $F_{5}$. (a) Detection of fault group and faulty switches; (b) Free-wheeling mode detection.

Figures 15 and 16 show the experimental results for the proposed fault detection and faulty switch localization under the simultaneous open-switch faults in $S_{1}, S_{2}$ and $S_{4}$ of $\mathrm{FG}_{6}$, and under the simultaneous open-switch faults in $S_{1}, S_{4}$ and $S_{6}$ of $\mathrm{FG}_{7}$, respectively. As explained in Table 1 , these two fault conditions give the same fault signature in current waveforms as shown in Figures 15a and 16a. Because only two positive or negative currents exist, $N_{n z c}$ is equal to 2. Following the procedures in Table 2, these fault groups $\mathrm{FG}_{6}$ or $\mathrm{FG}_{7}$ can be separated with the other remaining groups. Thus, the simultaneous open-switch faults in $S_{1}$ and $S_{4}$ are only clear and the additional open-switch fault either in $S_{2}$ or in $S_{6}$ is not sure according to Table 5 . 


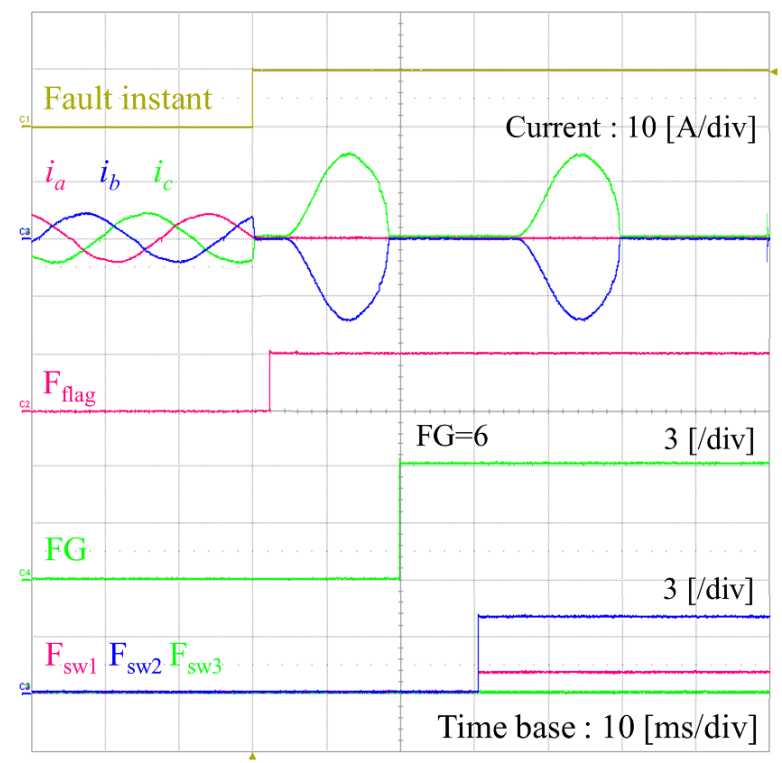

(a)

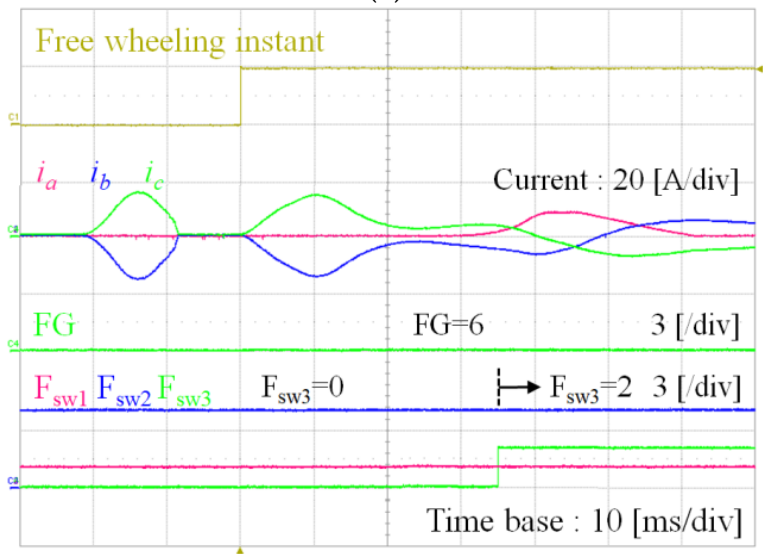

(b)

Figure 15. Experimental results for the proposed fault detection and localization under the simultaneous open-switch faults in $S_{1}, S_{2}$, and $S_{4}$ of $\mathrm{FG}_{6}$. (a) Detection of fault group and faulty switches; (b) Free-wheeling mode detection.

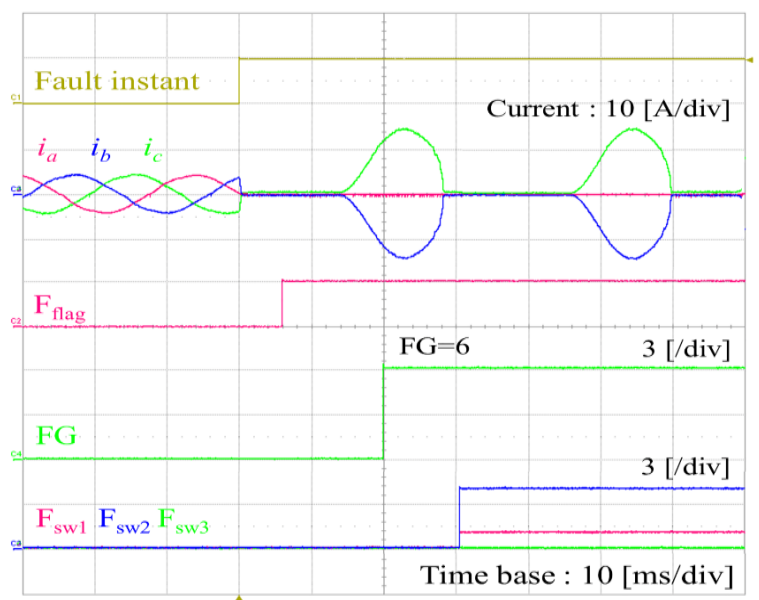

(a)

Figure 16. Cont. 


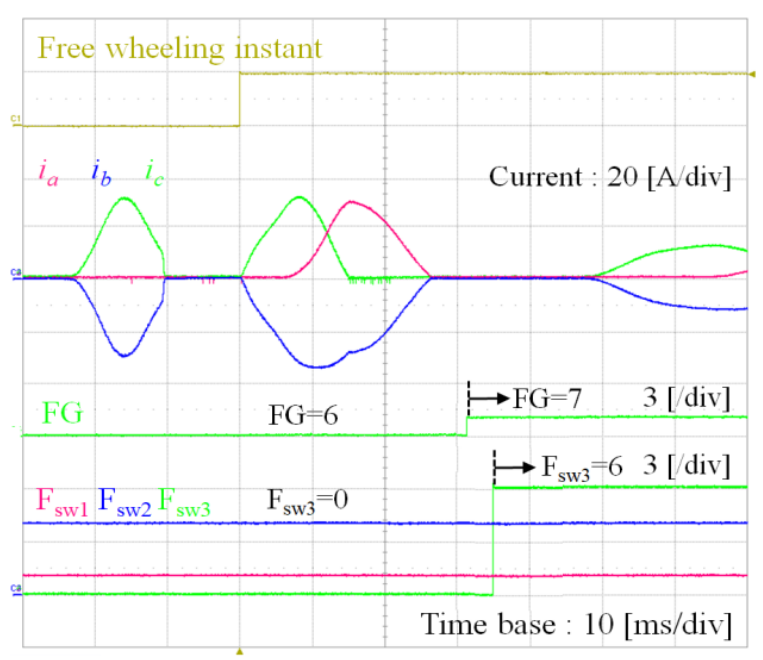

(b)

Figure 16. Experimental results for the proposed fault detection and localization under the simultaneous open-switch faults in $S_{1}, S_{4}$, and $S_{6}$ of $\mathrm{FG}_{7}$. (a) Detection of fault group and faulty switches; (b) Free-wheeling mode detection.

To investigate the remaining additional open-switch fault, the negative free-wheeling mode test is employed as shown in Figures $15 b$ and $16 b$. Whereas $c$-phase negative current exists in Figure $15 b$ during the negative free-wheeling mode test, it does not exist in Figure 16b. Thus, in addition to the simultaneous open-switch faults in $S_{1}$ and $S_{4}$, the remaining additional open-switch can be detected as $S_{2}$ in Figure 15 and as $S_{6}$ in Figure 16. As a result, the final detection results in the condition of Figure 15 are $\mathrm{FG}=6, \mathrm{~F}_{\mathrm{sw} 1}=1, \mathrm{~F}_{\mathrm{sw} 2}=4$, and $\mathrm{F}_{\mathrm{sw} 3}=2$, which indicates that the fault belongs to $\mathrm{FG}_{6}$ and the open-switch faults occur in $S_{1}, S_{4}$ and $S_{2}$ as shown in Figure $15 \mathrm{~b}$. On the other hand, the final detection results in the condition of Figure 16 are $F G=7, F_{s w 1}=1, F_{s w 2}=4$, and $F_{s w 3}=6$ as shown in Figure 16b. Figure 17 shows the experimental results for the proposed fault detection and faulty switch localization during acceleration period under the same simultaneous open-switch faults with Figure 16.

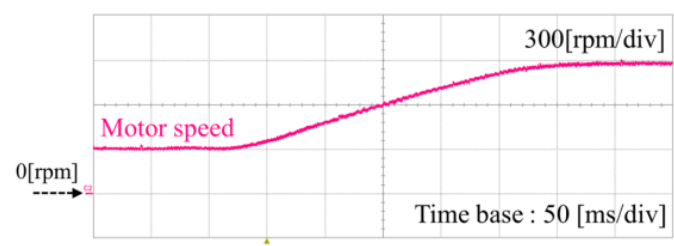

(a)

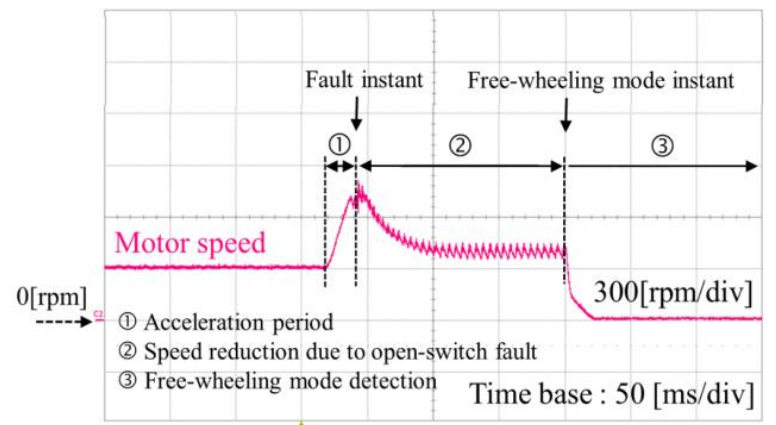

(b)

Figure 17. Cont. 


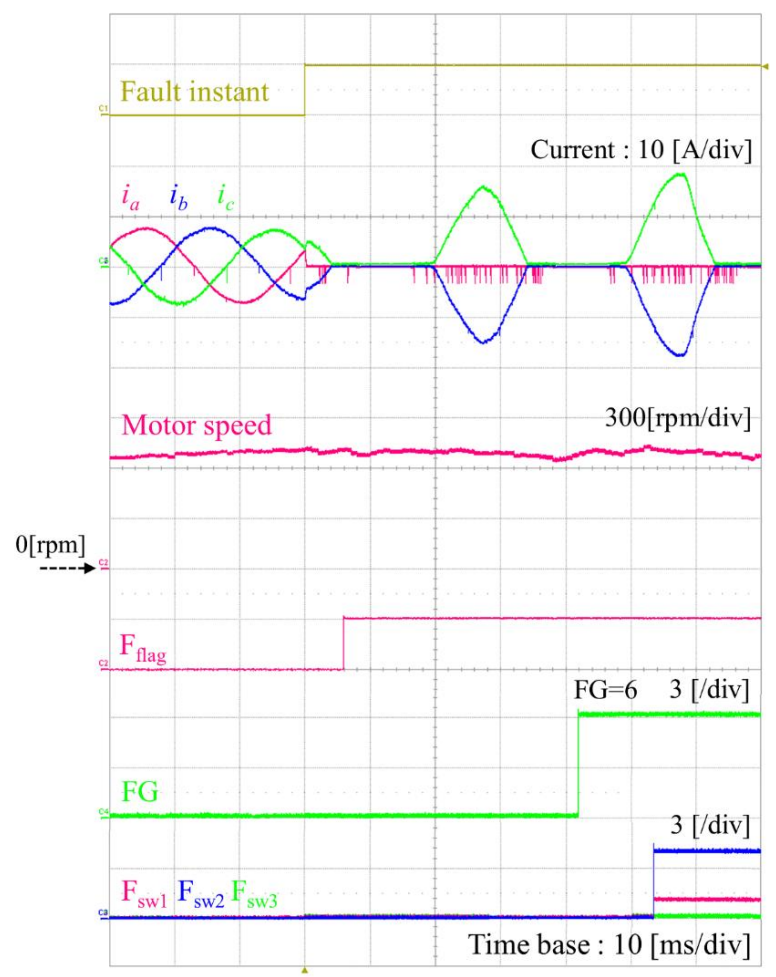

(c)

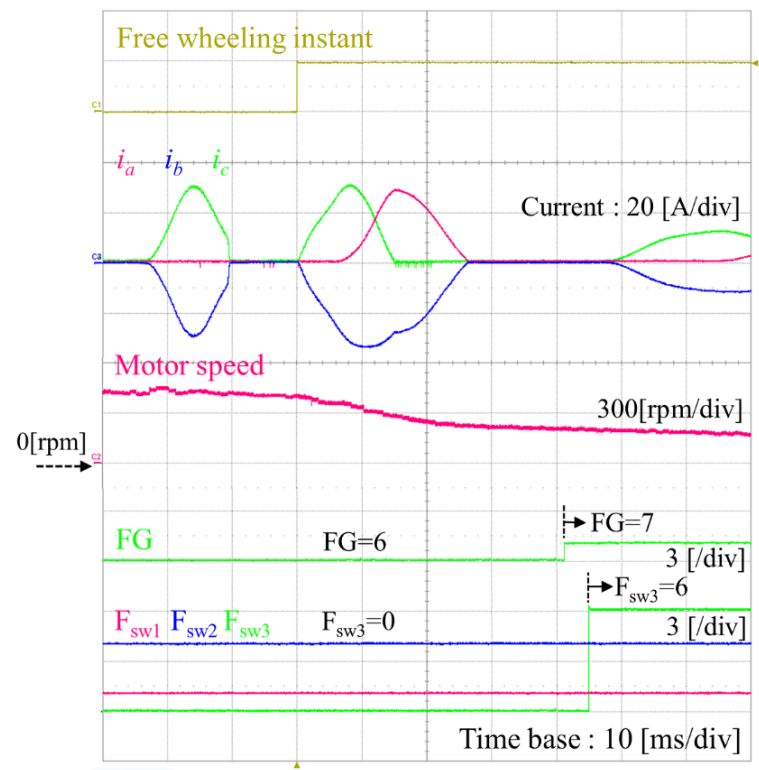

(d)

Figure 17. Experimental results for the proposed fault detection and localization under the simultaneous open-switch faults in $S_{1}, S_{4}$ and $S_{6}$ of $F_{7}$ during acceleration period. (a) Speed profile during acceleration period; (b) Speed variation during the entire operation of detection algorithm; (c) Detection of fault group and faulty switches; (d) Free-wheeling mode detection.

Figure 17a shows the speed profile during acceleration period and Figure $17 \mathrm{~b}$ shows the motor speed variation during the entire operation of detection algorithm including acceleration period. Even when the speed is increasing, the fault occurrence can be effectively detected as shown in Figure 17c. Section 4, it can clearly detect both the fault group and faulty switches as shown in Figure 17d. Through the experiments under various fault conditions, it has been clearly demonstrated that the proposed 
fault diagnosis scheme works effectively and reliably, even when the inverter has simultaneous open faults in three multiple switches. It is confirmed from the experimental results that the proposed diagnosis scheme works well in a practical drive system with a sufficient accuracy and rapidness.

\section{Conclusions}

In order to overcome the limitations of conventional diagnosis schemes, this paper has presented a reliable and practical on-line fault localization scheme for a PWM inverter-fed PMSM drive system even when the inverter has simultaneous open faults in up to three switches. An open-switch fault is usually initiated by an accidental over-current, or electrical and thermal stresses. This fault may induce secondary damage in the drive system since it is easily propagated and produces a continuous harmful effect on other system components. The open-switch faults in inverters occur in a very complicated manner. Due to this reason, it was only recently in a few references that real-time diagnosis schemes under open-switch faults in simultaneous switches have been presented. However, to alleviate the complexity and precision issues, until now most of the conventional fault diagnosis schemes have confined the open fault problem to only two simultaneous open-switches, which is not generally the case. Even though the fault detection is simple and immediate, the exact fault localization is not simple task, especially when there are open faults in three simultaneous switches because different open-switch fault locations may develop the same fault signature.

To extend the open fault problems to a general case, main objective of this study is to realize a reliable online fault localization algorithm under simultaneous (up to three) open-switch conditions without requiring any extra hardware or sensors so the algorithm can be easily installed in the main $\mathrm{CPU}$ of a commercial drive system. For the purpose of overcoming the limitations of existing diagnosis methods and avoiding the complexity in fault localization, the open faults in simultaneous switches are classified into seven different categories. In addition to using the fault signature developed by each of the seven fault groups, this paper employs a free-wheeling mode detection to identify all the simultaneous open-switches in a reliable and systematic way. To verify the feasibility and practical usefulness of the proposed on-line fault localization scheme, the entire system has been implemented on a digital controller by using a TMS320F28335 DSP. Experimental results under various open fault conditions are presented to validate the usefulness of the proposed fault diagnosis scheme.

Acknowledgments: This work was supported by the Research Program "Complex research center for materials \& components of railway" [16RTRP-B084184-04] funded by the Ministry of Land, Infrastructure and Transport of the Korean government.

Author Contributions: Jae-Hwan Song and Kyeong-Hwa Kim conceived the main concept of the control structure and developed the entire system. Jae-Hwan Song carried out the research and analyzed the numerical data with the guidance from Kyeong-Hwa Kim. Jae-Hwan Song and Kyeong-Hwa Kim collaborated to prepare the manuscript.

Conflicts of Interest: The authors declare no conflict of interest.

\section{References}

1. Choi, J.H.; Kim, S.H.; Yoo, D.S.; Kim, K.H. A diagnostic method of simultaneous open-switch faults in inverter-fed linear induction motor drive for reliability enhancement. IEEE Trans. Ind. Electr. 2015, 62, 4065-4077. [CrossRef]

2. Kim, K.H.; Choi, D.U.; Gu, B.G.; Jung, I.S. Fault model and performance evaluation of an inverter-fed permanent magnet synchronous motor under winding shorted turn and inverter switch open. IET Electr. Power Appl. 2010, 4, 214-225. [CrossRef]

3. Lu, B.; Sharma, S.K. A literature review of IGBT fault diagnostic and protection methods for power inverters. IEEE Trans. Ind. Electr. 2009, 45, 1770-1777.

4. Yang, S.; Bryant, A.; Mawby, P.; Xiang, D.; Tavner, P. An industry-based survey of reliability in power electronic converters. IEEE Trans. Ind. Appl. 2011, 47, 1441-1451. [CrossRef] 
5. Grubic, S.; Aller, J.M.; Bin, L.; Habetler, T.G. A survey of testing and monitoring methods for stator insulation systems in induction machines. In Proceedings of the International Conference on Condition Monitoring and Diagnosis, Beijing, China, 21-24 April 2008; pp. 196-203.

6. Hanna, R.A.; Prabhu, S. Medium-voltage adjustable-speed drives-users' and manufactures' experiences. IEEE Trans. Ind. Appl. 1997, 33, 1407-1415. [CrossRef]

7. Kattha, D.; Bose, B.K. Investigation of fault modes of voltage-fed inverter system for induction motor drive. IEEE Trans. Ind. Appl. 1994, 30, 1028-1038.

8. Choi, U.M.; Jeong, H.G.; Lee, K.B.; Blaabjerg, F. Method for detecting an open-switch fault in a grid-connected NPC inverter system. IEEE Trans. Power. Electr. 2012, 27, 2726-2739. [CrossRef]

9. Duan, P.; Xie, K.G.; Zhang, L.; Rong, X. Open-switch fault diagnosis and system reconfiguration of doubly fed wind power converter used in a microgrid. IEEE Trans. Power Electr. 2011, 26, 816-821. [CrossRef]

10. Xiong, Y.; Cheng, X.; Shen, Z.J.; Mi, C.; Wu, H.; Garg, V. A prognostic and warning system for power-electronic modules in electric, hybrid, and fuel cell vehicles. In Proceedings of the Conference Record of the 2006 IEEE Industry Applications Conference, Tampa, FL, USA, 8-12 October 2006; pp. 1578-1584.

11. Bolognani, S.; Zordan, M.; Zigliotto, M. Experimental fault-tolerant control of a PMSM drive. IEEE Trans. Ind. Electr. 2000, 47, 1134-1141. [CrossRef]

12. Peuget, R.; Courtine, S.; Rognon, J.P. Fault detection and isolation on a PWM inverter by knowledge-based model. IEEE Trans. Ind. Appl. 1998, 34, 1318-1326. [CrossRef]

13. Estima, J.O.; Cardoso, A.M. Fast fault detection, isolation and reconfiguration in fault-tolerant permanent magnet synchronous motor drives. In Proceedings of the IEEE Energy Conversion Congress and Exposition (ECCE), Raleigh, NC, USA, 15-20 September 2012; pp. 3617-3624.

14. Mendes, A.M.S.; Cardoso, A.J.M. Fault diagnosis in a rectifier-inverter system used in variable speed ac drives, by the average current Park's vector approach. In Proceedings of the EPE'99, 8th European Conference on Power Electronics Applications, Lausanne, Switzerland, 7-9 September 1999; Volume 99, pp. 1-9.

15. An, Q.T.; Li, S.; Sun, L.Z. Current residual vector-based open-switch fault diagnosis of inverters in PMSM drive systems. IEEE Trans. Power Electr. 2015, 30, 2814-2827. [CrossRef]

16. Campos-Delgado, D.U.; Pecina-Sánchez, J.A.; Espinoza-Trejo, D.R.; Arce-Santana, E.R. Diagnosis of open-switch faults in variable speed drives by stator current analysis and pattern recognition. IET Electr. Power Appl. 2013, 7, 509-522. [CrossRef]

17. Nieznanski, W.J.; Cichowski, A. Open-transistor fault diagnostics in voltage-source inverters by analyzing the load currents. IEEE Trans. Ind. Electr. 2009, 56, 4681-4688.

18. Estima, J.O.; Cardoso, A.J.M. A new algorithm for real-time multiple open-circuit fault diagnosis in voltage-fed PWM motor drives by the reference current errors. IEEE Trans. Ind. Electr. 2013, 60, 3496-3505. [CrossRef]

19. Estima, J.O.; Cardoso, A.J.M. A new approach for real-time multiple open-circuit fault diagnosis in voltage-source inverters. IEEE Trans. Ind. Appl. 2011, 47, 2487-2494. [CrossRef]

20. Estima, J.O.; Freire, N.M.; Cardoso, A.M. Recent advances in fault diagnosis by Park's vector approach. In Proceedings of the IEEE Workshop on Electrical Machines Design, Control and Diagnosis (WEMDCD), Paris, France, 11-12 March 2013; pp. 279-288.

21. Kim, K.H.; Gu, B.G.; Jung, I.S. Online fault-detecting scheme of an inverter-fed permanent magnet synchronous motor under stator winding shorted turn and inverter switch open. IET Electr. Power Appl. 2011, 5, 529-539. [CrossRef]

22. Song, J.H.; Kim, K.H. Fast detection of open-switch fault using moving filter for a PWM VSI-fed PMSM drive system. Int. J. Appl. Eng. Res. 2017, 12, 932-939.

23. Song, J.H.; Kim, K.H. Reliable Open-Switch Fault Localization Scheme in Multiple Switches for Inverter-Fed Permanent Magnet Synchronous Machine Drives; Taylor and Francis Inc.: Abingdon, UK, to be published.

24. Ribeiro, R.L.A.; Jacobina, C.B.; Silva, E.R.C.; Lima, A.M.N. Fault detection of open-switch damage in voltage-fed PWM motor drive systems. IEEE Trans. Power Electr. 2003, 18, 587-593. [CrossRef]

25. Choi, C.; Lee, W. Design and evaluation of voltage measurement-based sectoral diagnosis method for inverter open switch faults of permanent magnet synchronous motor drives. IET Electr. Power Appl. 2012, 6, 526-532. [CrossRef]

26. Kim, T.J.; Lee, W.C.; Hyun, D.S. Detection method for open-circuit fault in neutral-point-lamped inverter systems. IEEE Trans. Ind. Appl. 2009, 56, 2754-2763. 
27. Rodriguez-Blanco, M.A.; Claudio-Sanchez, A.; Theilliol, D.; Vela-Valdes, L.G.; Sibaja-Teran, P.; Hernandez-Gonzalez, L.; Aguayo-Alquicira, J. A failure-detection strategy for IGBT based on gate-voltage behavior applied to a motor drive system. IEEE Trans. Ind. Electr. 2011, 58, 1625-1633. [CrossRef]

28. An, Q.T.; Sun, L.Z.; Zhao, K.; Sun, L. Switching function model-based fast-diagnostic method of open-switch faults in inverters without sensors. IEEE Trans. Power Electr. 2011, 26, 119-126. [CrossRef]

29. Karimi, S.; Poure, P.; Saadate, S. Fast power switch failure detection for fault tolerant voltage source inverters using FPGA. IET Power Electr. 2009, 2, 346-354. [CrossRef]

30. Park, B.H.; Lee, K.J.; Kim, R.Y.; Kim, T.S.; Ryu, J.S.; Hyun, D.S. Simple fault diagnosis based on operating characteristic of brushless direct-current motor drives. IEEE Trans. Ind. Electr. 2011, 58, 1586-1593. [CrossRef]

31. Freire, N.M.A.; Estima, J.O.; Cardoso, A.J.M. A voltage-based approach without extra hardware for open-circuit fault diagnosis in closed-loop PWM AC regenerative drives. IEEE Trans. Ind. Electr. 2014, 61, 4960-4970. [CrossRef]

32. Campos-Delgado, D.U.; Espinoza-Trejo, D.R. An observer-based diagnosis scheme for single and simultaneous open-switch faults in induction motor drives. IEEE Trans. Ind. Electr. 2011, 58, 671-679. [CrossRef]

33. Aktas, M.; Turkmenoglu, V. Wavelet-based switching faults detection in direct torque control induction motor drives. IET Sci. Meas. Technol. 2010, 4, 303-310. [CrossRef]

34. Gou, B.; Ge, X.; Wang, S.; Feng, X.; Kuo, J.B.; Habetler, T.G. An open-switch fault diagnosis method for single-phase PWM rectifier using a model-based approach in high-speed railway electrical traction drive system. IEEE Trans. Power Electr. 2016, 31, 3816-3826. [CrossRef]

35. Jung, S.M.; Park, J.S.; Kim, H.W.; Cho, K.Y.; Youn, M.J. An MRAS-based diagnosis of open-circuit fault in PWM voltage-source inverters for PMSM drive systems. IEEE Trans. Power Electr. 2013, 28, 2514-2526. [CrossRef]

36. Zidani, F.; Diallo, D.; Benbouzid, M.E.H.; Nait-said, R. A fuzzy-based approach for the diagnosis of fault modes in a voltage-fed PWM inverter induction motor drive. IEEE Trans. Power Electr. 2008, 55, 586-593. [CrossRef]

37. TMS320F28335 Digital Signal Controller (DSC)_Data Manual; Texas Instruments: Dallas, TX, USA, 2008.

(C) 2018 by the authors. Licensee MDPI, Basel, Switzerland. This article is an open access article distributed under the terms and conditions of the Creative Commons Attribution (CC BY) license (http:/ / creativecommons.org/licenses/by/4.0/). 